\title{
Ocean-scale modelling of the distribution, abundance, and seasonal dynamics of the copepod Calanus finmarchicus
}

\author{
Douglas C. Speirs ${ }^{1, *}$, William S. C. Gurney ${ }^{1,2}$, Michael R. Heath ${ }^{2}$, Werner Horbelt ${ }^{3}$, \\ Simon N. Wood $^{3}$, Beverly A. de Cuevas ${ }^{4}$ \\ ${ }^{1}$ Department of Statistics and Modelling Science, University of Strathclyde, Glasgow G1 1XH, UK \\ ${ }^{2}$ FRS Marine Laboratory, PO Box 101, Victoria Road, Aberdeen AB11 9DB, UK \\ ${ }^{3}$ Department of Statistics, University of Glasgow, Glasgow G12 8QQ, UK \\ ${ }^{4}$ Southampton Oceanography Centre, Southampton SO14 3ZH, UK
}

\begin{abstract}
The copepod Calanus finmarchicus is widely distributed over the sub-polar Atlantic and dominates the mesozooplanktonic biomass in that region. Despite this, all previous $C$. finmarchicus population modelling studies have been spatially and temporally limited. In this paper we present results from a fully stage-resolved model in a domain spanning the entire geographic range of the species $\left(30\right.$ to $80^{\circ} \mathrm{N}$ and $80^{\circ} \mathrm{W}$ to $90^{\circ} \mathrm{E}$. The model was driven by temperature and transport from the Ocean Circulation and Climate Advanced Modelling project (OCCAM) and phytoplankton food derived from satellite (SeaWiFS) sea-surface colour observations. The resulting quasi-stationary yearly cycle was assessed against seasonally resolved maps of continuous plankton recorder observations, winter cruise data on the distribution of diapausers, and time series from locations distributed over the North Atlantic. The model's high computational efficiency permitted its free parameters to be selected to yield a good correspondence with the field data. We were also able to explore the effects of changing the assumptions regarding diapause and mortality. By falsifying alternative models we conclude that (1) a fixed fraction of each surface generation enters diapause, (2) overwintering individuals enter diapause at the end of the fifth copepodite stage, and (3) mortality is an increasing function of temperature. Finally, we demonstrate that the demographic impact of transport is limited, except in shelf seas and at the edges of the distribution; nevertheless, there is a very high level of population connectivity over the whole domain.
\end{abstract}

KEY WORDS: Calanus finmarchicus $\cdot$ Structured population model $\cdot$ Diapause $\cdot$ Temperaturedependent mortality $\cdot \mathrm{CPR} \cdot \mathrm{OCCAM} \cdot \mathrm{SeaWiFS}$

Resale or republication not permitted without written consent of the publisher

\section{INTRODUCTION}

The copepod Calanus finmarchicus (Gunnerus) is among the most important and widely distributed zooplanktonic species of the sub-polar North Atlantic ecosystem (Jaschnov 1970, Conover 1988). Its numerical abundance is extremely high, and in many regions it dominates the mesoplanktonic biomass (Head et al. 2003). Through grazing on phytoplankton it contributes substantially to oceanic secondary production (Aksnes \& Blindheim 1996), and it is a major species of prey for a wide range of commercially exploited fish (Dalpadado et al. 2000, Lynch et al. 2001). On account of its key status, there is now a considerable body of laboratory and field data on C. finmarchicus, and there have been numerous attempts to understand its demography through modelling studies.

A major problem for all models of Calanus finmarchicus lies in the complexity of its life cycle and interaction with the physical and biotic environment. Development involves a progression from eggs through 6 naupliar stages (N1 to N6) and 5 copepodite stages (C1 
to C5) before reaching adulthood (C6). There is at least 1 generation in the spring, usually followed by 1 or 2 more generations before the autumn (Conover 1988, Pedersen et al. 2001). Overwintering individuals are principally C5s which sink to depths often exceeding $1000 \mathrm{~m}$ (Heath et al. 2004) where they enter a diapause state (Hirche 1997). The development time depends strongly on water temperature and to a lesser degree phytoplankton abundance (Campbell et al. 2001). Adult fecundity also shows dependence on food and temperature (Hirche et al. 1997). As well as the local impact of environmental factors, ocean currents affect demography by transporting individuals through spatially heterogeneous habitats (Speirs et al. 2004) and determine which regions have sufficiently hydrographic retentiveness to allow persistent populations (Bryant et al. 1998).

Most modelling studies have avoided a simultaneous assault on all of these difficulties in favour of strategic simplifications. For example, non-spatial models have been used in describing locally homogeneous environments such as fjords (Miller \& Tande 1993), in strategic population dynamics studies (Hind \& Gurney 1998, Hind et al. 2000), and in investigations of comparative demography (Heath et al. 2000a). Some models ignore horizontal transport, focusing instead on incorporating Calanus finmarchicus into vertically structured physical/biological ecosystems (Carlotti 1996, Carlotti \& Radach 1996, Carlotti \& Wolf 1998). Several studies have modelled spatial processes in C. finmarchicus populations using ensembles of Lagrangian particles (Slagstad \& Tande 1996, Heath et al. 1997, Miller et al. 1998, Pedersen et al. 2000, Speirs et al. 2004). Such models deal with transport in an intuitive way, but the computational demands of tracking large numbers of particles when representing continuous populations over large areas impose obvious practical limits on their spatial and temporal extent.

Recently, a number of authors have used Eulerian descriptions of Calanus finmarchicus in which the spatial domain is divided up into set of discrete cells (Bryant et al. 1997, Lynch et al. 1998, Tittensor et al. 2003, Zakardjian et al. 2003). These models are a more natural representation of the density of organisms continuously distributed over large areas, but the accurate characterization of both spatial and physiological structure by standard methods is computationally demanding. Gurney et al. (2001) therefore developed a novel discrete-time-space Calanus model which yielded results nearly identical to those of a comparable Lagrangian ensemble but with run times many orders of magnitude faster. This computationally efficient method was extended to a full model of $C$. finmarchicus over the NE Atlantic by Speirs et al. (2005).

In this paper we develop a model, based on the Speirs et al. (2005) approach, whose spatial domain spans the whole geographic range of Calanus finmarchicus. Over the North Atlantic C. finmarchicus displays distinct regional variations in abundance and seasonal cycle. For example, populations off the eastern seaboard of North America show peak abundances much earlier in the year than those to the south of Greenland, while those of the eastern Atlantic peak at an intermediate time (Planque et al. 1997). There is also considerable demographic variability between NE Atlantic sites (Heath et al. 2000a). The first goal of our study is to determine whether these large scale geographic patterns can be captured by a single model involving simple responses to local environmental conditions, or whether more complex variations in vital rates, perhaps due to genetically distinct subpopulations, are implicated.

One of the significant challenges in modelling Calanus finmarchicus is that a number of aspects of its biology are poorly understood. For example, the mechanisms involved in the initiation and termination of diapause are currently a matter for debate (see Hirche 1997, Hind et al. 2000, Irigoien 2004, Speirs et al. 2005, and references therein). Similarly, there are several field-based estimates of stagedependent mortality for $C$. finmarchicus (e.g. Eiane et al. 2002, Ohman et al. 2004), but these are still too limited to be useful in identifying the functional relationships between mortality and population density, and environmental factors. Therefore, the second goal of our study is to identify a model of diapause and mortality that yields a good correspondence between predictions and field data. Although in the following sections we focus mainly on results from our final model, in the section 'Diapause and mortality', we outline the process of model falsification that led us to it.

Much of the existing theoretical work on Calanus finmarchicus, and the field observations on which it is based, has focussed on shelf seas because these are important fisheries areas (MERCINA 2004). However, it has become increasingly evident that shelf populations are dependent on processes occurring on much larger ocean-basin scales. For example, yearly variations in abundance in the North Sea are associated with changes in the supply of spring recruits from oceanic overwintering stock (Colebrook 1986), and from the Faroe-Shetland Channel in particular (Heath et al. 1999a). In the western Atlantic, the Georges Bank population is sustained by recruitment from a number of basins in the Gulf of Maine and the Scotian Shelf (Hannah et al. 1998, Lynch et al. 1998, Miller et al. 1998). The main oceanic centres of population production appear to be in the hydrographically retentive gyre systems in the Labrador/ Irminger Sea and the Norwegian Sea (Heath et al. 
2001, de Young et al. 2004). On the basis of simple calculations of renewal rates in these gyres, Aksnes \& Blindheim (1996) have argued that the reproductive capacity of $C$. finmarchicus is sufficiently great to dominate over transport at this large scale. Nevertheless, the effects of basin-scale circulation and exchange between the gyres, remains largely unknown (Tittensor et al. 2003). Thus, our final goal, addressed in the 'Transport and domain connectivity' section, is to examine the demographic impact of transport and the extent to which the entire North Atlantic Calanus stock is connected.

\section{THE MODEL}

\section{Overview}

The model is discrete in space and time, and spans the whole of the North Atlantic from 30 to $80^{\circ} \mathrm{N}$ and from $80^{\circ} \mathrm{W}$ to $90^{\circ} \mathrm{E}$ (Fig. 1), over which the population is distributed over a regular grid of cells $\left(0.5^{\circ}\right.$ longitude by $0.25^{\circ}$ latitude). We distinguish between 2 update processes. Biological updates advance the population in each cell with respect to development, reproduction, and death. Transport updates redistribute the population between cells as a result of physical transport. Output from a separate physical model provides the temperature and flow-field drivers for the biological and transport updates. The biological model also requires the annual cycle of food (phytoplankton carbon) in each cell, which we derive from satellite sea-colour observations. Sea ice seasonally covers northern regions of the domain, and this annual cycle of cover is also obtained from satellite observations. Our target year for the simulations was 1997, since this was the year of the Trans-Atlantic Study of Calanus (TASC) programme (see 'Field data' below). A mathematical definition of the model can be found in Appendix 1 (see Appendix 1 at www.int-res.com/articles/suppl/ m313p173_app.pdf), together with the parameter values used in the runs.

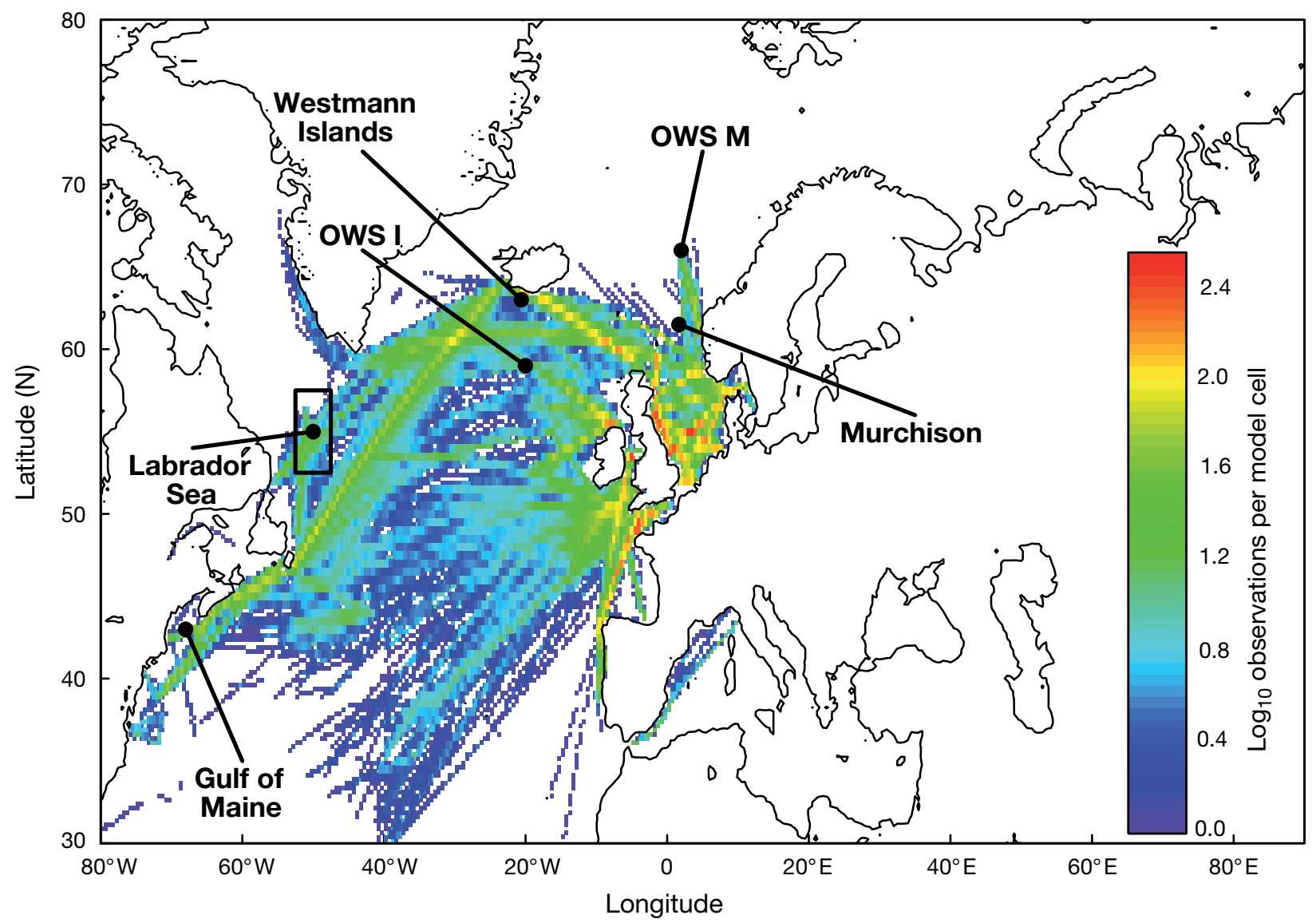

Fig. 1. The model domain. The colour scale indicates the total number of observations from the continuous plankton record (CPR) located in each model cell. Stations where time series were extracted from the model output for comparison with sampling data are indicated. In the Labrador Sea no independent time series data were available, so a times series was derived from the CPR by smoothing with respect to day of the year all the values within $2.5^{\circ}$ latitude and longitude of the sampling point (box). 


\section{The biological model}

The biological model has 3 categories of individuals. Surface-developing juveniles are comprised of eggs (E), 6 naupliar stages (N1 to N6), and 5 copepodite stages (C1 to C5). Diapausers (C5d) are individuals that have descended in the water column in order to overwinter at depth. Adults (C6) are reproductive individuals that have ceased growing.

The egg to adult development rate depends on temperature and food abundance (Eq. A16), but the proportional time spent in each stage remains constant. Development can therefore be represented by an index running from 0 for a newly laid egg to 1 for an adult. Dividing this into equal-width classes means that each morphological stage maps on to a set of consecutive model classes. All individuals progress along the index at the same rate, so at a biological update the surviving contents of all the classes are ready to be moved to the next class, thereby avoiding numerical diffusion in the egg to adult time (Gurney et al. 2001). The first class receives the reproductive output of the adults, and individuals leaving the last C5 class, are added to the adults. The timing of these updates depends on the growth rate (and hence the seasonal cycle of temperature and food), and so is irregular in space and time (Eq. A8). Computational efficiency is maintained by calculating the annual cycle of update intervals for every cell in advance.

The per capita egg-production rate is a saturating function of food with an asymptote that increases with temperature (Eq. A27). Field estimates of mortality rates are sparse, but it is clear that they are strongly stage-dependent (Eiane et al. 2002; Ohman et al. 2004). We cannot use these estimates directly since they represent total mortality, whereas we need to distinguish between background and density-dependent rates in order to achieve population regulation. Instead, we model mortality as the sum of a stagedependent background rate, and a product of this background rate and a density-dependent rate (Speirs et al. 2005). In order to preserve the observed between-stage relativities, the background rates are taken to be a fraction of those given by Eiane et al. (2002), while the density-dependent component is proportional to the total local Calanus finmarchicus biomass density. At very low food densities we increase the total mortality sharply to prevent unrealistic persistence in the absence of food. As discussed in the 'Diapause and mortality' section, we also found it necessary to make the background mortality a non-linear increasing function of temperature (Eqs. A20 to A25).

For overwintering, a fixed fraction of the last C5 class is diverted to a diapausing $\mathrm{C} 5$ class instead of progressing to adulthood (Eq. A18). We assume that successful overwintering requires a minimum water depth of $100 \mathrm{~m}$, and individuals attempting to enter diapause in shallower water are removed from the population. Development in diapause is divided into classes in a manner similar to the surface developers, and depends on the temperature at depth (Eq. A17). Mortality occurs at a constant density-independent rate. Speirs et al. (2005) showed that the observed synchrony in the spring emergence of overwinterers in the Norwegian Sea cannot be explained by mechanisms involving the internal state of individuals because transport mixes individuals with different environmental histories. They proposed that a photoperiod of about $12 \mathrm{~h}$ may cue the final emergence to the surface $100 \mathrm{~m}$, a model that we adopt here (Eq. A13). As discussed in full in Speirs et al. (2005), the model diapausers do not necessarily correspond to individuals in true physiological diapause. Rather, they represent all overwinterers below the top $100 \mathrm{~m}$, whether they are in ascent, decent, or in true diapause, and photoperiod cues only the final movement into this surface layer.

\section{Physical model}

Velocity and temperature fields were provided by the Ocean Circulation and Climate Advanced Modelling project (OCCAM) (Webb et al. 1998). OCCAM is a z-level global ocean model which solves the ocean primitive equations using finite differences on a horizontal staggered Arakawa ' $\mathrm{B}$ ' grid. It is based on the GFDL MOM version of the Bryan-Cox-Semtner ocean model, but includes a free surface and improved advection schemes. A regular longitude-latitude grid is used for the Pacific, Indian and South Atlantic oceans. A rotated longitude-latitude grid, with poles on the equator in the Indian and Pacific oceans, is used for the Arctic and North Atlantic oceans. The model was started from the Levitus annual mean temperature and salinity fields, and then driven by surface forcing using ECMWF 6-hourly varying wind stress. Here we use the output for 1997 which had been stored as $5 \mathrm{~d}$ mean velocities and temperatures on a regular $0.5^{\circ} \mathrm{N}$ by $0.25^{\circ} \mathrm{E}$ grid.

In the population model, we assume that surface individuals experience temperatures and velocities occurring at a depth of $20 \mathrm{~m}$ in the water column. The depth at which overwintering occurs is very variable in space, ranging from $100 \mathrm{~m}$ to over $1500 \mathrm{~m}$. We therefore use a Gaussian kernel smooth applied to observed median overwintering depths from various locations (Heath et al. 2004) to produce a map of diapause depths. Where the smoothed value exceeds the bathymetric depth, the bathymetric depth minus $10 \mathrm{~m}$ is assumed. The temperatures and velocities at these 
depths are those used to drive the overwintering population.

The transport updates occur at weekly intervals. The transfer matrices which define redistribution and mixing at these updates are determined from the flow fields using the methodology proposed by Gurney et al. (2001). For each cell in the population model we use the OCCAM velocities to track an ensemble of 100 particles started from the cell centre at the start of the week. We assume that transport is purely passive such that each particle is displaced deterministically by a timedependent flow field interpolated in time and space from the OCCAM output. Since closed deterministic trajectories are unlikely (Bryant et al. 1998), long-term persistence of any population must rely on horizontal diffusion, as demonstrated in a 1-D context by Speirs \& Gurney (2001). We therefore also randomly perturb the velocities by a white-noise velocity simulating horizontal diffusion at the chosen rate. At the end of the week the number of particles arriving in each target cell is counted and used as a measure of the transition probability between source and target cells.

\section{Food}

The only observations which have appropriate spatial and temporal coverage to supply phytoplankton carbon are satellite measurements of sea-surface colour. Since no observations of this type are available for our target year (1997) we make use of $8 \mathrm{~d}$ averaged observations from the SeaWiFS satellite from 1998 to 2000. However, as noted by Speirs et al. (2005) and Clarke et al. (2005), there is an unsatisfactory correspondence between time series inferred from SeaWiFS and field measurements from the same locations. Clarke et al. (2005) therefore developed a statistical methodology in which thin plate regression splines model a set of directly observed local chlorophyll concentrations as a function of satellite observations, bathymetry and time of year. Generalized crossvalidation was used to choose an overall smoothing parameter and the relative scale of the covariates. In a series of tests of its applicability to the NE Atlantic, Clarke et al. (2005), showed that regional features of monthly maps from the model are in good correspondence with those observed in direct plots from the satellite observations, while the local time-series derived from the model are in considerably better correspondence with in situ observations than those derived directly from satellite data. We apply the same methodology over the current model domain. Since satellite observations can only record sea-surface colour, we use only field samples from the top $5 \mathrm{~m}$ of the water column. We assume that these are well correlated with the average chlorophyll concentration experienced by surface-dwelling Calanus over their vertical distribution. Phytoplankton carbon abundance is derived from the statistical model by assuming that $1 \mathrm{mg} \mathrm{m}^{-3}$ of chl a is equivalent to $40 \mathrm{mg} \mathrm{C} \mathrm{m}^{-3}$ (in the middle of the range of values given by Parsons et al. 1984).

\section{Sea ice}

In the northern part of the model domain we need to account for the effect of seasonal sea-ice cover. The phytoplankton carbon fields are statistical fits that extend into regions which are in reality covered by ice. When and where sea ice is present we therefore need to mask the fitted food field by setting the values to zero. This mask is derived from 1997 satellite percentage ice cover from the Defence Meteorological Satellite Program's (DMSP) special sensor microwave/imager (SSM/I) (Comiso 1999). For each cell in the Calanus model the latitude and longitude are calculated and the sea-ice concentration found in the nearest pixel of the polar stereographic grid used with the satellite data using the conversion equations of Snyder (1982). If the pixel contains ice then our model grid cell is considered masked. This process is repeated at weekly intervals to produce a sequence of ice masks representing the yearly cycle of ice cover.

\section{FIELD DATA}

\section{Overview}

The computational efficiency of the model allows the simulated year to be run to a quasi-stationary state (which is reached within a few years from even arbitrary initial conditions), and to carry out extensive parameter explorations. Quantitative and qualitative comparison with field data permits the output to be optimized in relation to free parameters, notably those relating to diapause and mortality (Appendix 1). For this we draw on field data from a variety of sources, detailed in the following subsections. The confrontation with the data takes 3 forms. The continuous plankton recorder (CPR) data contains a sufficiently large number of spatially and temporally dispersed observations to allow comparison with the model predictions at the level of bimonthly distribution maps showing seasonally shifting spatial patterns of abundance. Secondly, data from a variety of net-sampling programmes (the TASC data, the Ocean Weather Ship India data, and the Gulf of Maine data) are treated as time series 
and compared to model predictions from fixed locations. Finally, we use a composite of winter net-sampling surveys (the diapauser abundance surveys) to provide a single distribution map of overwintering individuals. Fig. 1 shows the locations of the time series samples, and extent and density of the CPR data.

\section{The TASC time series}

As part of the EU TASC project, depth-resolved copepodite densities were obtained at locations close to Ocean Weather Ship (OWS) M $\left(66^{\circ} \mathrm{N}, 2^{\circ} \mathrm{E}\right)$ between 24 February and 17 December 1997 using a $180 \mu \mathrm{m}$ mesh opening and closing multinet (Heath et al. 2000a, Hirche et al. 2001). Depth layers were typically $0-50,50-100,100-200,200-300,300-500$, 500-1000 and 1000-1600 m, although in practice these varied between sampling dates. The concentrations $\left(\mathrm{m}^{-3}\right)$ of copepodite stages were converted to stage abundances $\left(\mathrm{m}^{-2}\right)$ at $0-100$ and $100-1600 \mathrm{~m}$. In autumn and winter, the population in the deeper layer consisted mostly of individuals in C5, which we define as the diapausers. During spring and summer almost all individuals resided in the upper $100 \mathrm{~m}$. Also as part of TASC, sampling occurred at 2 locations near the Westmann Islands $\left(63^{\circ} 27.25^{\prime} \mathrm{N}, 20^{\circ} 00.00^{\prime} \mathrm{W}\right.$, depth $100 \mathrm{~m}$, and $63^{\circ} 22.20^{\prime} \mathrm{N}, 1^{\circ} 54.85^{\prime} \mathrm{W}$, depth $200 \mathrm{~m}$ ) (Gislason et al. 2000). The sites were visited on 29 occasions during 1997, and plankton was collected by vertically integrating hauls from $5 \mathrm{~m}$ above the seabed to the sea surface with a $200 \mu \mathrm{m}$ mesh, $56 \mathrm{~cm}$ Bongo net.

\section{Ocean Weather Ship India}

Although our simulated year is 1997, the shortage of time-series data from truly oceanic sites leads us to include some data sampled at OWS India $\left(59^{\circ} \mathrm{N}, 19^{\circ} \mathrm{E}\right)$ between 1971 and 1975 (Irigoien 1999). Roughly weekly samples were taken from March to October each year. Each sample involved oblique hauls of a Longhurst-Hardy plankton recorder (280 $\mu \mathrm{m}$ mesh) in which stage-resolved copepod samples were collected every $10 \mathrm{~m}$ from $500 \mathrm{~m}$ depth to the surface. As with the TASC time series we used the data from the top $100 \mathrm{~m}$ as representing the surface population and aggregated the data over all the years in order to get an impression of the typical seasonality at this location. We did not estimate diapauser abundance at this site because the maximum sampling depth of $500 \mathrm{~m}$ was too shallow in relation to the $2000 \mathrm{~m}$ bathymetric depth to observe the bulk of the overwintering population except transiently during descent and ascent.

\section{Gulf of Maine}

In 1995 as part of the US GLOBEC an extensive programme of zooplankton sampling was initiated in the Gulf of Maine and Georges Bank (Durbin et al. 2000). Over the first half of each year Calanus finmarchicus copepodite densities (number $\mathrm{m}^{-3}$ ) were estimated over varying depth intervals down to the bottom using a $1 \mathrm{~m}^{2}$ MOCNESS fitted with $0.15 \mathrm{~mm}$ mesh nets. Using the data from 1995 to 1999, we calculated number $\mathrm{m}^{-2}$ over the top $100 \mathrm{~m}$ and from $100 \mathrm{~m}$ to the bottom. We only did this where the bathymetry exceeded $200 \mathrm{~m}$ in order to exclude very shallow areas, including Georges Bank itself, which show a distinct seasonality (Durbin et al. 2000) and where diapausing does not occur. The samples cover a substantial geographic area (approximately -40 to $43^{\circ} \mathrm{N}$ and 65 to $70^{\circ} \mathrm{E}$ ) and so are not strictly time series, and show a great deal of variability. Nevertheless, the overall abundance levels characteristic of this region, and the timing of the main demographic changes, provided a useful target for the model predictions.

\section{Diapauser abundance surveys}

Multi-annual composite data on the spatial distribution of overwintering stages were compiled from sampling at sea during November, December and (to a minor extent) January, between 1994 and 2002 (Heath et al. 2004). Sampling was carried out at 398 stations from 17 surveys across the northern North Atlantic from Newfoundland to NW Norway. For approximately half of the stations, C1 to C6 Calanus finmarchicus were resolved to stage and enumerated by microscopic examination of depth layered zooplankton samples collected with an opening and closing $200 \mu \mathrm{m}$ mesh net system. This mesh aperture has been shown to retain $>95 \%$ of $C$. finmarchicus stage $\mathrm{C} 1$, increasing to $100 \%$ of C2 and later stages (Nichols \& Thompson 1991). At the remaining locations, only data from an optical plankton counter (OPC) (Focal Technologies) were available. The OPC had previously been calibrated by cross-correlation of particle counts with concurrent data from net samples, so that the count data could be reliably converted to numbers of stage C4 to C5 C. finmarchicus (Heath et al. 1999b, 2000b). At each station, net or OPC-derived estimates of the concentration (number $\mathrm{m}^{-3}$ ) of $\mathrm{C} 4$ plus $\mathrm{C} 5$ copepodites were averaged over $200 \mathrm{~m}$ depth intervals, gridded horizontally, and then integrated vertically taking account of the seabed depth where appropriate. From the net data we know that on average $80 \%$ of the population is in C5, and so the resulting values were reduced accordingly for comparison with the model. 


\section{The continuous plankton record}

The CPR (Warner \& Hays 1994) is an instrument towed by ships of opportunity to obtain a continuous record of zooplankton abundance at a depth in the water column of approximately $10 \mathrm{~m}$. Subsequent analysis resolves this record into abundance measurements (number $\mathrm{m}^{-3}$ ) for a number of taxa, among them Calanus finmarchicus, but only copepodite Stages 5 and 6 are resolved to the species level.

Our principal use of the CPR is to generate seasonal maps of Calanus finmarchicus C5 to C6 density by averaging the accepted numbers falling within each model cell over bimonthly intervals. We use a data set of 170149 values recorded from the North Atlantic between 1958 and 2002. The large number of years and the moderate seasonal resolution permitted images with sufficient spatial coherence, despite the necessarily irregular nature of the CPR sampling, to make visual comparisons with the model output. The model output of surface C5 to C6's is expressed in number $\mathrm{m}^{-2}$ (i.e. depth-integrated over the top $100 \mathrm{~m}$ ). This means that we need a scaling factor converting number $\mathrm{m}^{-2}$ to $\mathrm{CPR}$ number $\mathrm{m}^{-3}$ at $10 \mathrm{~m}$ depth. We obtained an approximate value by plotting scaled smoothed trends of the annual cycle of CPR values in the vicinity of sites where there is independent time series data, and comparing these to the data while varying the scaling factors. We found that multiplying the CPR smooths by 20 led to abundances comparable to those of the time series at all sites (see 'Testing the model').

The CPR data on Calanus finmarchicus shows different long-term trends in different regions of the North Atlantic (Greene et al. 2003), and within regions the seasonal cycle can change with time (Beare et al. 1998). A necessary preliminary was therefore to examine the effect of restricting the data to values collected in the 1990s (bracketing our 1997 simulation year). As expected, the spatial coverage was unsatisfactorily sparse, even with the coarse bimonthly temporal averaging. However, at the qualitative level of the comparisons used in this paper, the 1990s' data produced spatial and temporal patterns that were entirely consistent with those of the entire data set.

\section{TESTING THE MODEL}

Fig. 2 illustrates the seasonal cycle of the combined C5 to C6 stages (left-hand panels) and the diapausing C5s (right-hand panels) produced by the model. Early in the year virtually all the population is in diapause, except in the vicinity of the Gulf of Maine, Scotian Shelf, and Grand Banks where the high food levels allow limited survival and reproduction of the surface population. By April, the diapausers have emerged and the spatial distribution surface population shadows that of the diapausers. In June the surface population is dominated by the next generation. The highest densities occur along the line running southwest to northeast along the North Atlantic Drift and Norwegian coastal current where intermediate temperatures favour fast development and high reproductive output. Spread of the population into the North Sea is also apparent by this time. Diapausing individuals have also begun to appear, particularly in the fasterdeveloping southern parts of the distribution. Later in the summer (August) the first surface generation is declining in the warmer water areas, but peaking in the Labrador Sea. The distinction between the population centres located in the 2 gyre systems of the Labrador-Irminger Sea and the Norwegian Sea is clear. By now, there is also a substantial accumulation of diapausers over most of the distribution. By October, there is a new, but much smaller, increase in the surface population as another generation comes through, and a further increase in the diapausing population. By December, most of the stock is in diapause once again.

We begin the confrontation with the data by comparing the time series of early copepodites ( $\mathrm{C} 1$ to $\mathrm{C} 4 \mathrm{~s})$ at the various locations, with the corresponding model prediction (Fig. 3). The free model parameters were chosen to yield as good a fit as possible for these time series (Appendix 1). There is generally a very respectable match between the observed and predicted relative abundances and seasonal cycles, especially the timing of the first generation. We do particularly well at the Westmann Islands and at OWS Mike (Fig. 3a,b), as we would expect since these data sets were used in the development of our NE Atlantic prototype model (Speirs et al. 2005). In the Gulf of Maine (Fig. 3e) the average abundances are well predicted by the model but the predicted peak abundance occurs noticeably late.

Fig. 4 also shows time series data and the matching model output, this time for the C5 to C6s. At OWS Mike (Fig. 4b) the photoperiod-cued exit from diapause results in a good match to the timing and magnitude of the appearance of C6s from the overwintering stock, and the model also captures the subsequent seasonal changes in abundance, in particular the large first generation peak. The timing and size of the firstgeneration peak at the Westmann Islands (Fig. 4a), produced by individuals transported onto the shelf rather than by the offspring of in situ overwintering stock, is also good. Because it is believed that the Labrador Sea is an important population centre for Calanus finmarchicus (Head et al. 2000, 2003, Tittensor et al. 2003), we would ideally like true time-series 
Surface C5-C6s

Day 49 (February)
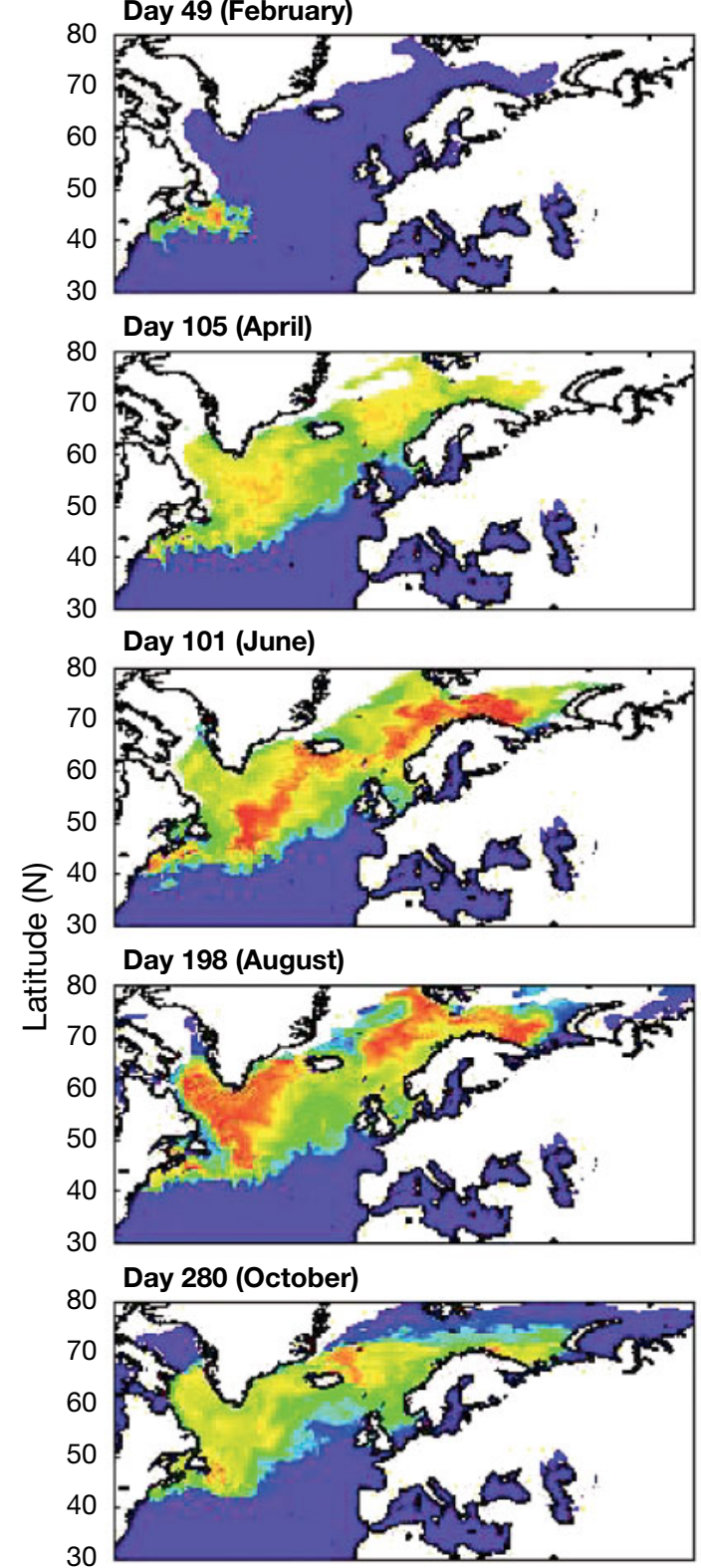

Day 350 (December)

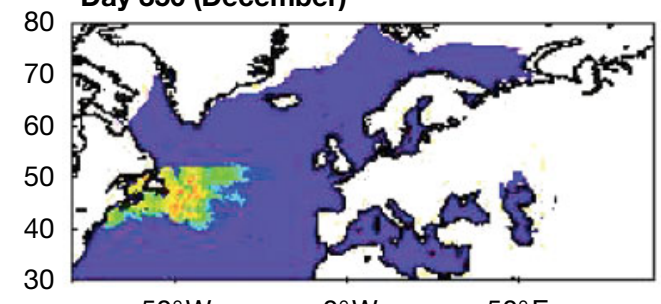

Diapausing C5s
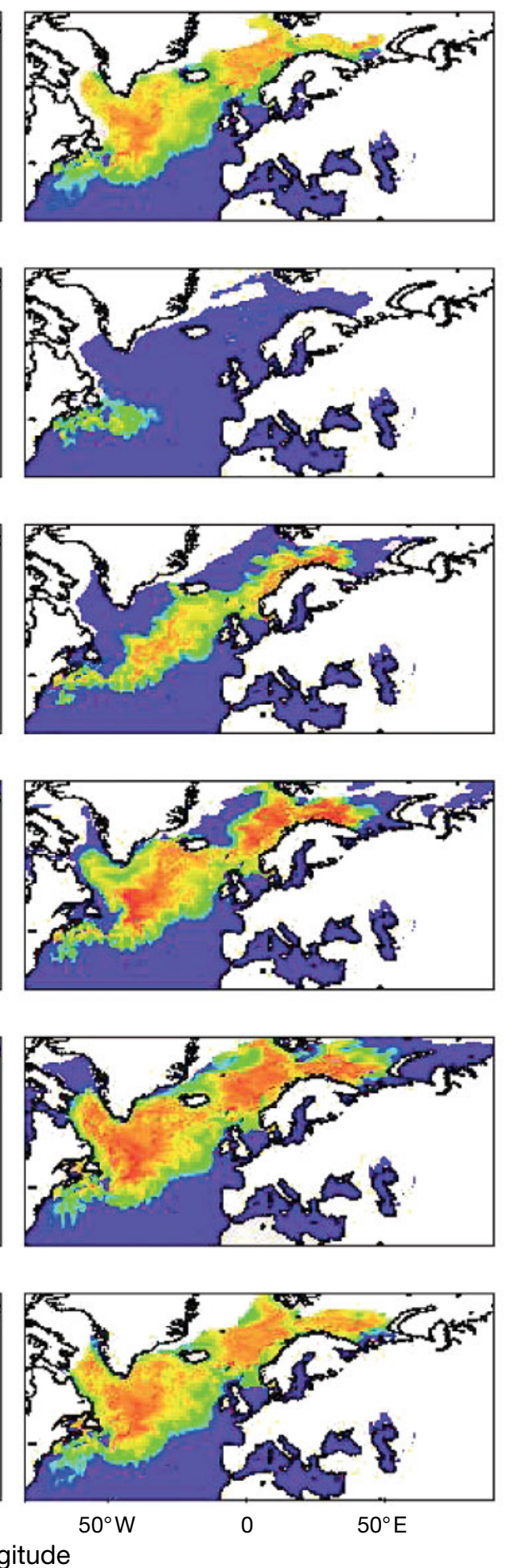

Fig. 2. Model output showing the seasonal cycle of late copepodites (C5 and C6) in the surface waters, and of C5 diapausing at depth. The day of the year, and the month in which it falls, are indicated 

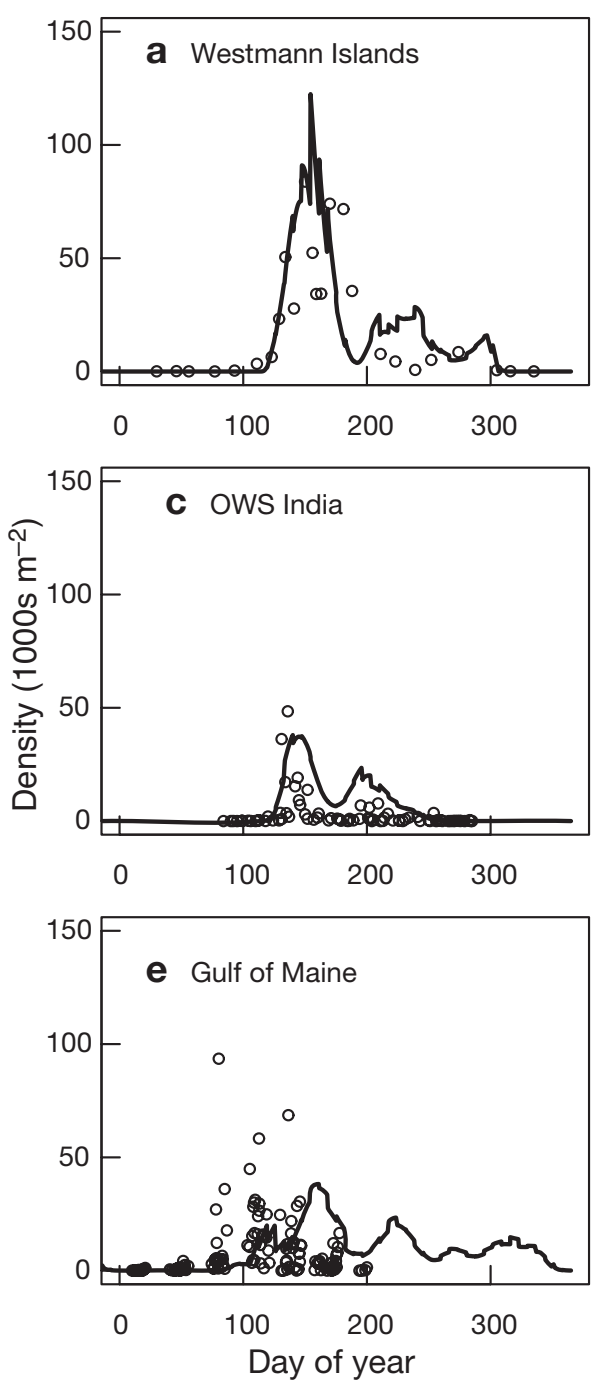

Fig. 3. Time series of the density of the combined C1 to C4 stages. Lines show the model predictions, circles show data from sampling programmes. Depth integrated over the top $100 \mathrm{~m}$ of the water column only a lower bound for the depthintegrated abundance of diapausers. The samples taken in December went to $1600 \mathrm{~m}$ and so are probably close to the true density of diapausers, and these samples are well predicted by the model.

For diapausers we also have synoptic data on their winter distribution of diapausing $\mathrm{C} 5 \mathrm{~s}$, and the observations and predictions of this are illustrated in Fig. 6. There is a good correspondence between the model and the data in the Norwegian Sea, where both show a pattern of low diapauser abundance in the west and higher abundances towards the Norwegian continental shelf. The model output also shows some of the Norwegian Sea overwintering population being transported through the FaroeShetland Channel, in agreement with the observations (Heath et al. 1999a, Harms et al. 2000). Both in the Labrador Sea and South of Iceland to the east of the Reykjanes Ridge, the predicted overwintering population shows plausible densities. The model overpredicts the observed densities in the Irminger Sea (between Greenland and Iceland) and in the central Atlantic.

In the final confrontation with data we compare the predicted seasonal changes in the distribution of surface

data from this region. In its absence we use a smooth through the CPR accepted values that are within $2.5^{\circ}$ of $55^{\circ} \mathrm{N}, 50^{\circ} \mathrm{W}$ (Fig. 1). In this key area, the model matches the strikingly late first generation peak (Fig. 4f). The correspondence between the data and the observations in the Gulf of Maine is quite good. The only site where the model shows a somewhat poor fit is at Murchison, where the main peak, although of correct magnitude, occurs too early.

Our final time series comparison involves diapauser abundances at the 2 sites where these are available (Fig. 5). At both sites the model shows approximately the correct maximum density of diapausers. The data show diapausers appearing earlier in the Gulf of Maine than at OWS Mike. This feature is echoed in the model run as a consequence of the longer generation time in cold waters of the Norwegian Sea. We apparently overpredict numbers at OWS Mike early in the year, but note that the maximum sampling depth varied between dates, so that the data points represent
C5 to C6s with those observed in the CPR (Fig. 7). Early in the year (January to February), both the data and the model show few C5 to C6s present in the surface except to the east of Newfoundland. By spring and early summer (May to June) the first surface generation dominates the abundances over much of the domain, although the model underpredicts densities in the North Sea somewhat. In late summer (July to August) the CPR displays its strongest signalthe very large peak of abundance in the southern Labrador Sea. This conspicuous feature is well reproduced by the model.

\section{DIAPAUSE AND MORTALITY}

Although the model presented in the previous sections is closely based on that of Speirs et al. (2005), its assumptions regarding diapause and mortality differ from that prototype model in several key regards. 

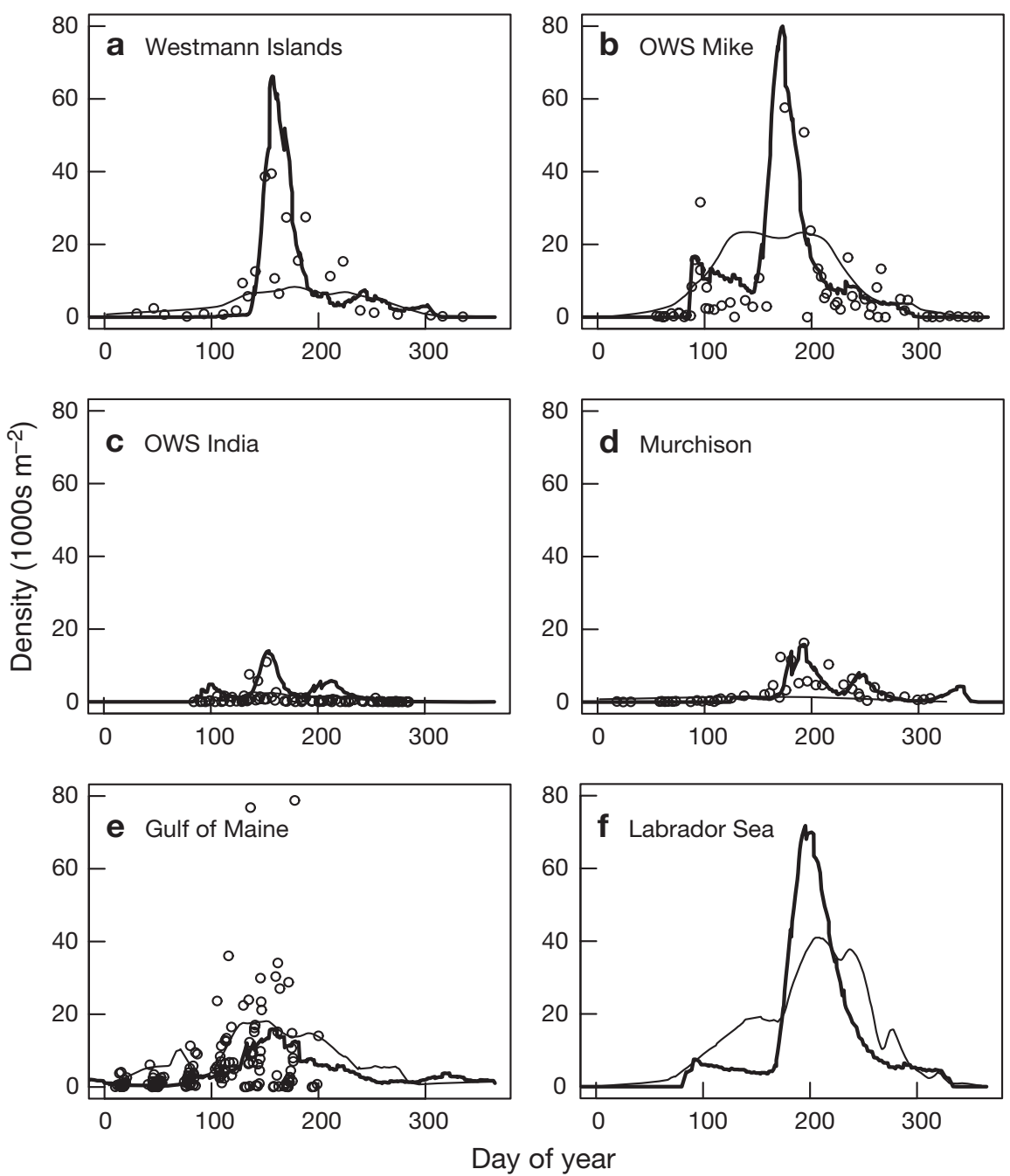

Fig. 4. Time series of the density of the combined C5 and C6 stages. Thick lines show the model predictions, while circles show data from sampling programmes, depth integrated over the top $100 \mathrm{~m}$ of the water column. For one location (Labrador Sea) we have no time series data, and instead use the smoothed CPR $\left(\mathrm{m}^{-3}\right)$ multiplied by a conversion factor of 20 (thin line). We also include the corresponding CPR smooth for the other locations to show the correspondence between the times series and the CPR when this scaling factor is assumed

Because of the impact of these modifications on our view of the ecology of Calanus finmarchicus, we now overview the rationale behind the changes and why they are critical to achieving the quality of fit seen in the previous section. In the discussion, we will address their biological implications.

The Speirs et al. (2005) model was developed for the NE Atlantic and successfully fitted to a variety of data from that region. At the outset of the work reported in this paper, we attempted simply to expand the spatial extent of the prototype model and assess the results in relation to the data from the whole Atlantic. The results were uniformly unsatisfactory, and showed 3 general failings which are illustrated in Fig. 8. Speirs et al. (2005) fitted their model to total surface copepodites, so unsurprisingly the model was able to achieve respectable matches to the $\mathrm{C} 1$ to $\mathrm{C} 4$ time series. By contrast, the fits to the C5 to C6 abundances were extremely poor. At OWS Mike, for example, although the peak of emerging overwinterers was well captured, the model seriously underpredicted the abundances of the subsequent generations (Fig. 8a). The second major failing was that the first appearance of diapausers occurred systematically too late in the year (Fig. 8b). Time series comparisons at other locations showed similarly egregious results. Most seriously of all, as well as generally underpredicting C5 to C6 abundances, the model singularly failed to predict the distinctive July to August peak in the southern Labrador Sea (Fig. 8c,d).

In the prototype model diapause entry was cued when individuals moulting from C4 to C5 encountered a food concentration that was below a fitted threshold value. However, reexamining the OWS Mike time series and focusing on the surface and diapausing C5s only (Fig. 9) reveals that diapausers appear almost as soon as the first surface generation comes through, and do so at a time when chlorophyll concentrations are still very high. An ancillary series of model runs, in which the food level initiating diapause was varied, confirmed that a threshold high enough to initiate diapause at the correct time suppressed all subsequent generations and caused population extinction over much of the domain. Thus, diapause entry cannot be cued by low food as we had previously hypothesized.

In further explorations of model variants we were unable to find any environmental cues that yield realistic timing of diapause at OWS Mike while retaining plausible patterns of abundance over the whole domain. Therefore, we now adopt a model involving a fixed fraction of the population entering diapause. Moreover, between about Day 180 and Day 220 there are significant numbers of $\mathrm{C} 5 \mathrm{~s}$ both in the surface and in the deeper water, and the surface C5 peak precedes the diapauser peak, while both are of similar magnitude. Since these must all be individuals from the first 


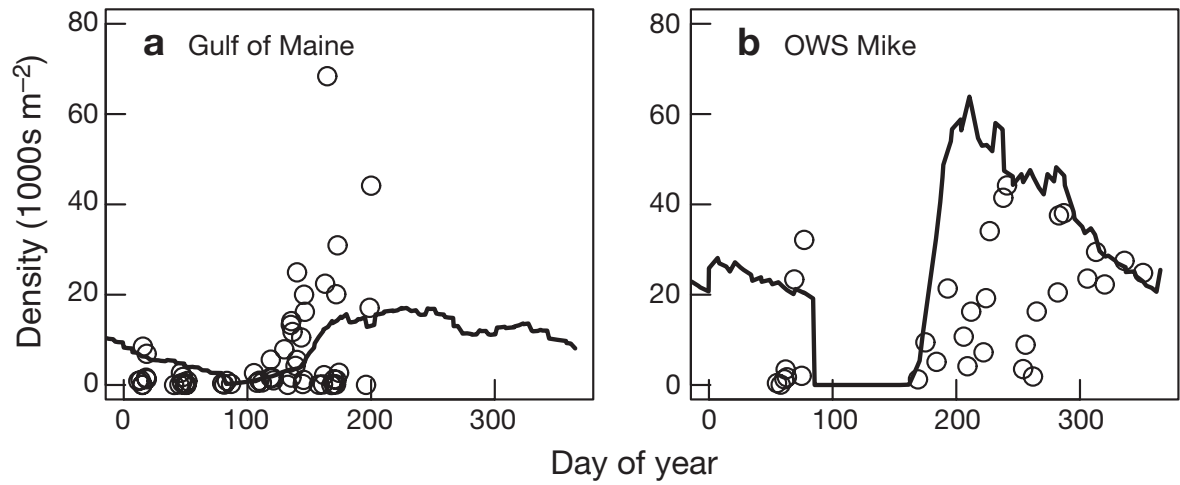

Fig. 5. Time series of the density of overwintering C5s. Lines show the model predictions, while circles show data from sampling programmes, depth integrated over the water column below $100 \mathrm{~m}$

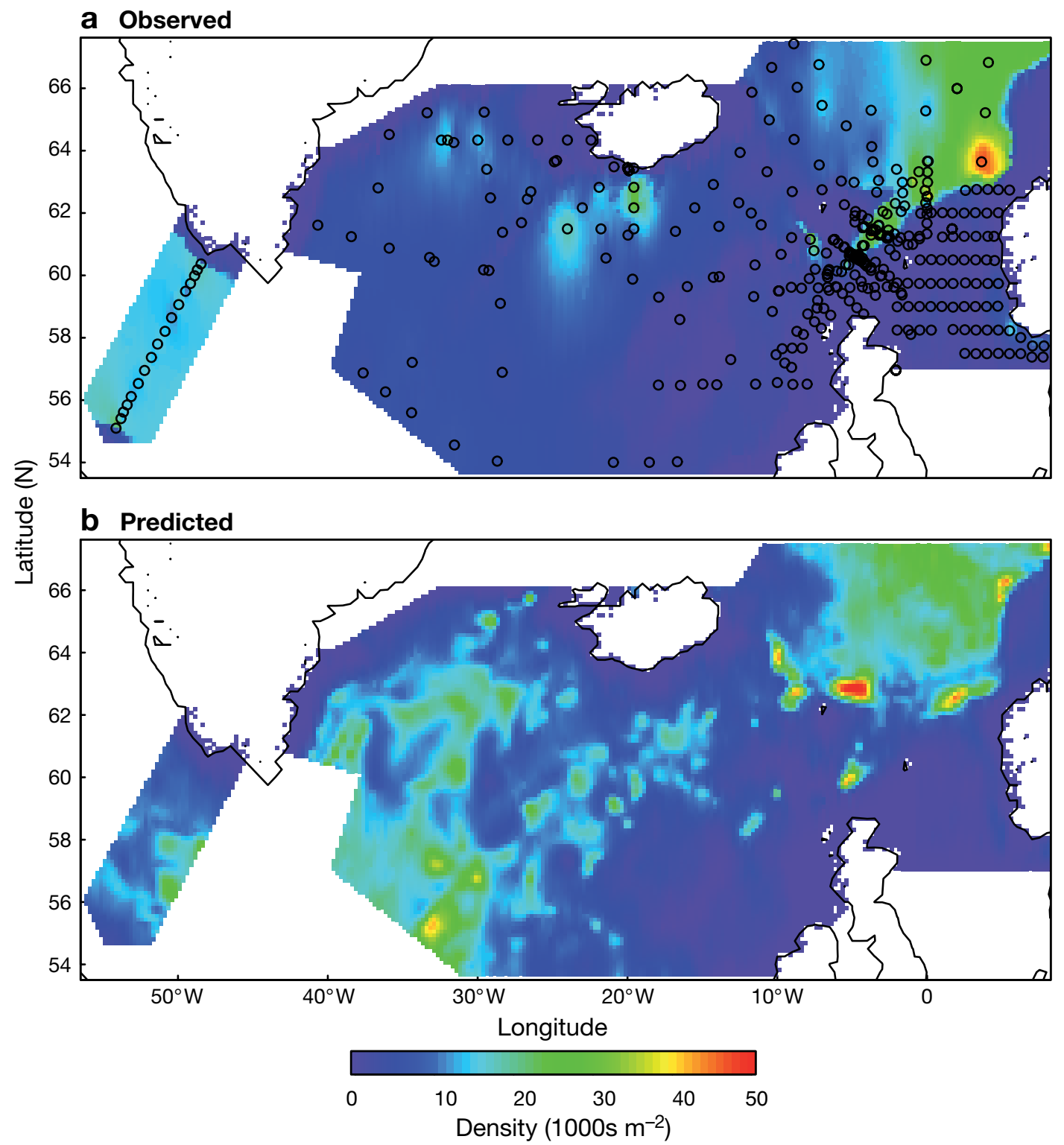

Fig. 6. Observed and predicted spatial distribution of overwintering C5s. The circles in the upper panel indicate the sampling locations at which observed values were obtained 

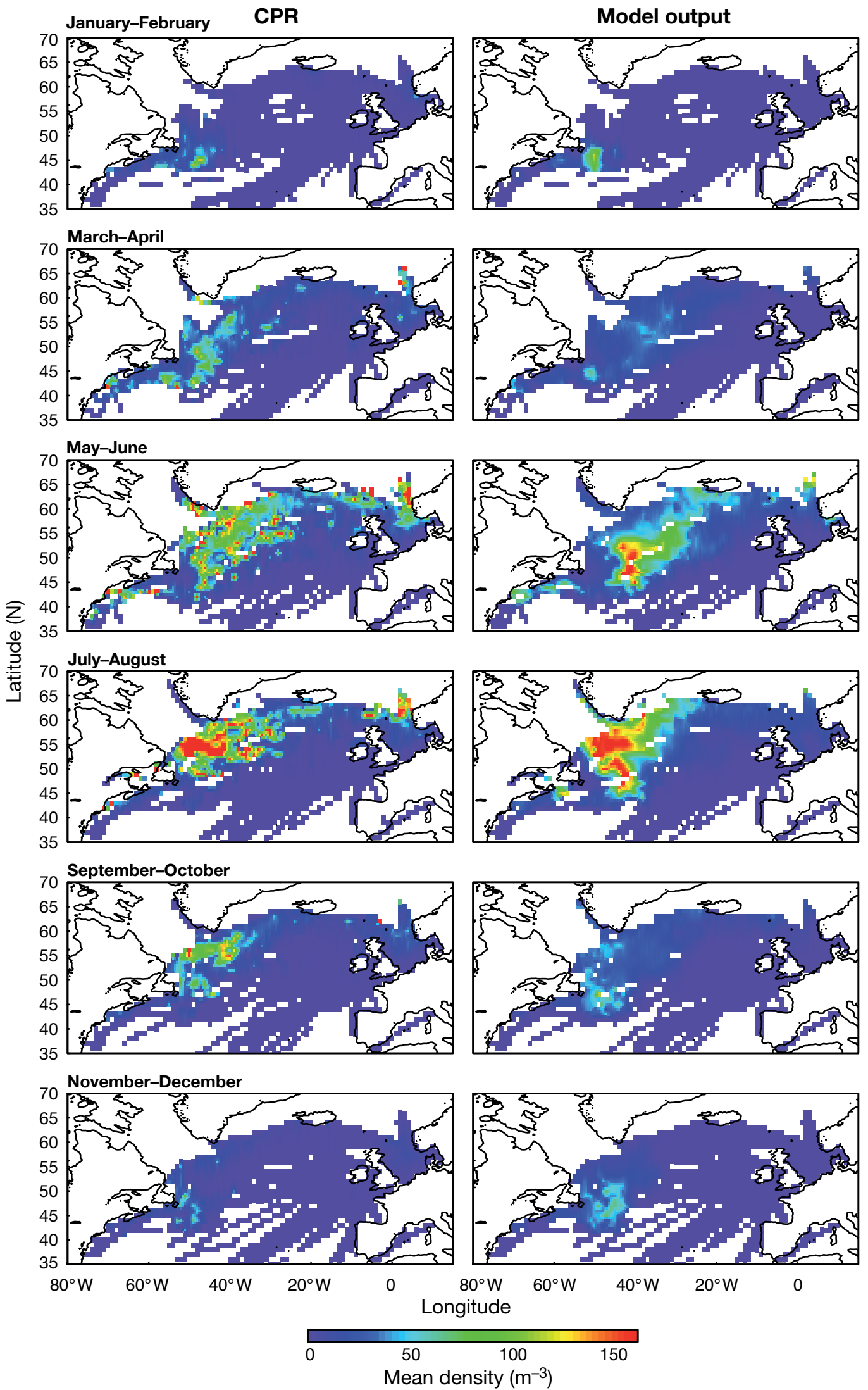

Fig. 7. Bimonthly mean CPR abundances (left-hand panels), and similarly averaged surface C5 to C6s predicted by the model (right-hand panels) 
a Surface C5's at OWS Mike

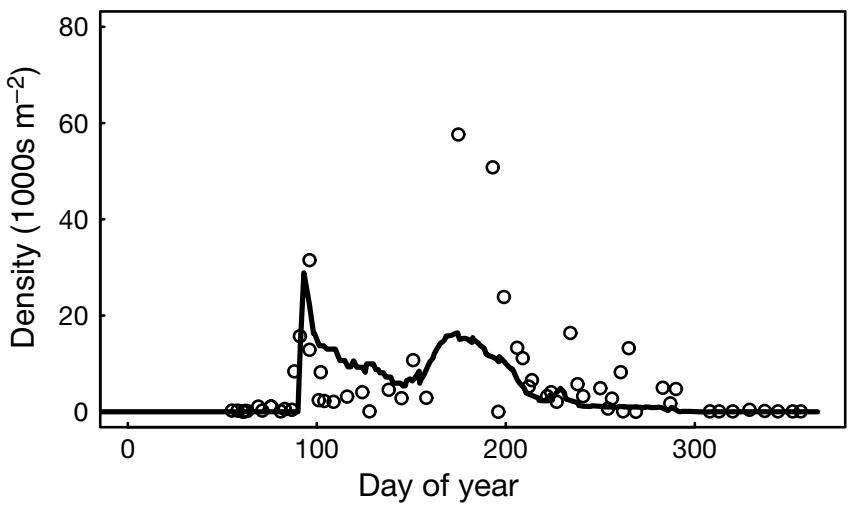

C Observed July-August surface C5-C6s

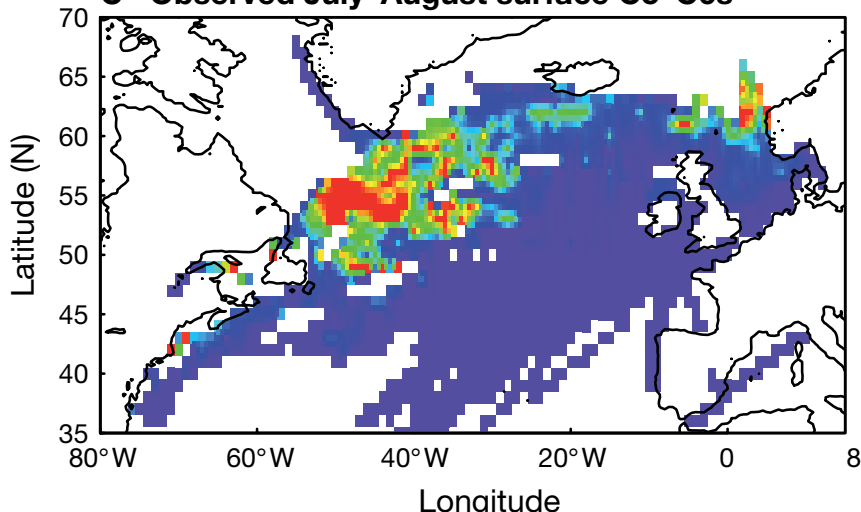

b Diapausing C5's at OWS Mike

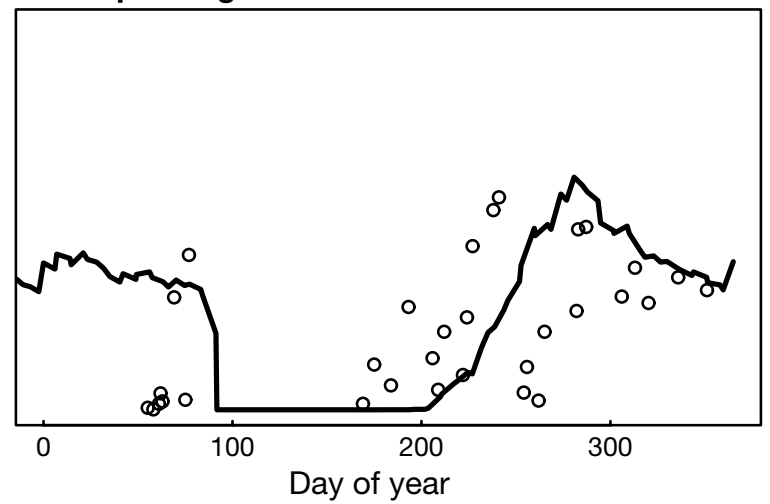

d Predicted July-August surface C5-C6s

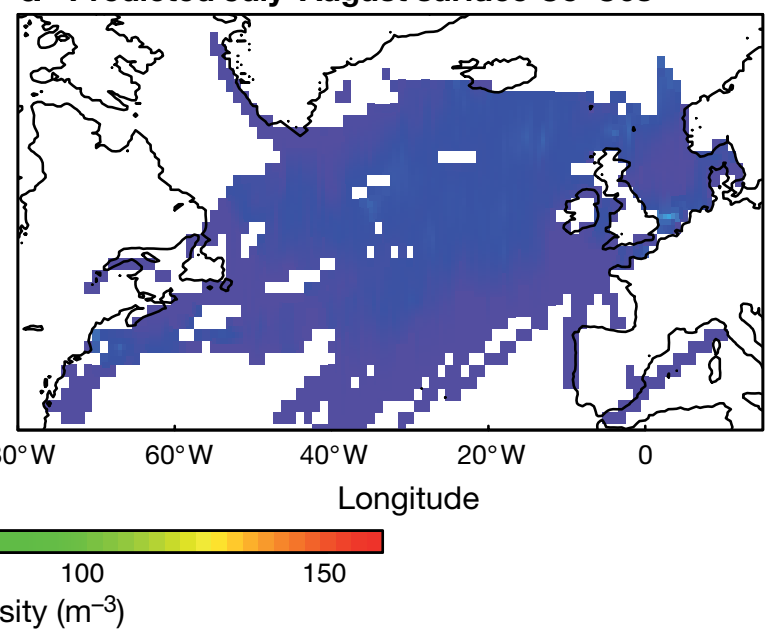

Fig. 8. Prototype model (Speirs et al. 2005) fit to the Ocean Weather Ship (OSW) Mike time-series of (a) surface and (b) diapausing C5 to C6. The corresponding comparison with the July to August CPR (c) observed and (d) predicted data

surface generation, this suggests that we are observing the same individuals from the first surface generation both in the surface layer and in diapause. This can only happen if the main stage at entry to diapause is towards the end of C5, rather than at the start of C5 as assumed in the prototype model.

These 2 changes still had no effect on the failure to reproduce the summer peak in abundance in the southern Labrador Sea. The main distinctive feature of this region compared to other areas of high Calanus finmarchicus abundance is its low temperature (Fig. 10). The immediate consequence of this is to increase the egg to adult development time. It might be expected that this should produce the late peak of C5 to C6s; however, because mortality is suffered over a longer period, the population is in fact suppressed. This suggests that a temperature-dependent mortality rate involving a non-linear increase in background mortality as temperature increases (Eqs. A21 \& A2) might result in a more satisfactory model.

The prototype model used the temperature-dependent fecundity function of (Heath et al. 2000a) which models a hypothesized reduction in fecundity at temperatures above $6^{\circ} \mathrm{C}$. The adoption of temperature-dependent mortality allows us to abandon this function in favour of one in which the maximum egg production rate increases linearly with temperature (Eq. A27), and which yields a good fit to the laboratory data of Hirche et al. (1997). For both models, the resulting decrease in net population production with increasing temperature is the main agent in limiting the southerly limit of the geographic distribution.

\section{TRANSPORT AND DOMAIN CONNECTIVITY}

The revisions lead to a successful model in which temperature, through the agency of development time and mortality, is the principle determinant of differences in the seasonal pattern over the domain. These improvements are to a large extent achieved by considering the effect of the local environment on local dynamics. This result suggests the possibility that physical transport over the domain may not be as 


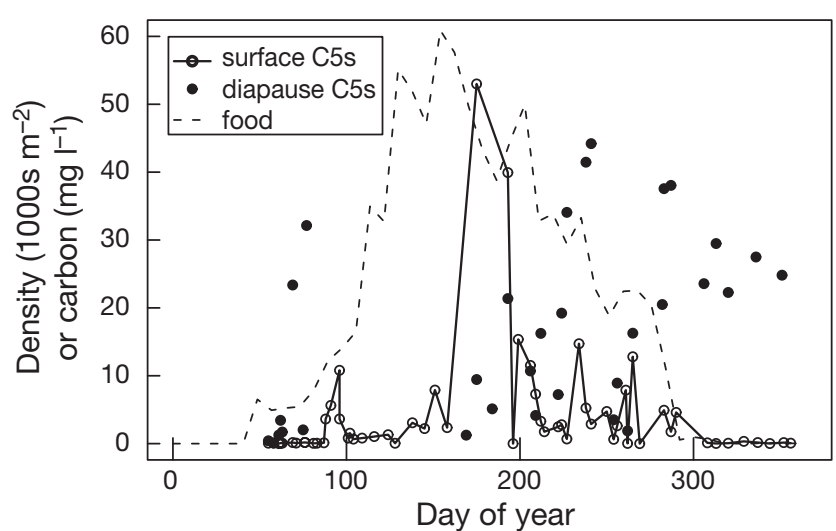

Fig. 9. C5s in the surface (top $100 \mathrm{~m}$ ) and in diapause (below $100 \mathrm{~m}$ ) at Ocean Weather Ship Mike, together with the corresponding food field (phytoplankton carbon) derived from SeaWiFS

important as is sometimes thought. In this section we therefore investigate the role of transport and domain connectivity in 2 model experiments.

In the first experiment we run the revised model to a quasi-stationary state but disable transport and compare the results to an otherwise identical run where transport operates normally. The distributions of surface C5 to C6s and diapausing C5s on Day 196 (midsummer when abundances are generally high) is presented in Fig. 11. Somewhat surprisingly switching off transport has a fairly modest effect on the overall appearance of the seasonal cycle and distribution. However, closer inspection of the surface C5 to C6 distributions reveals that transport extends the productive range of Calanus finmarchicus. In the central Atlantic,

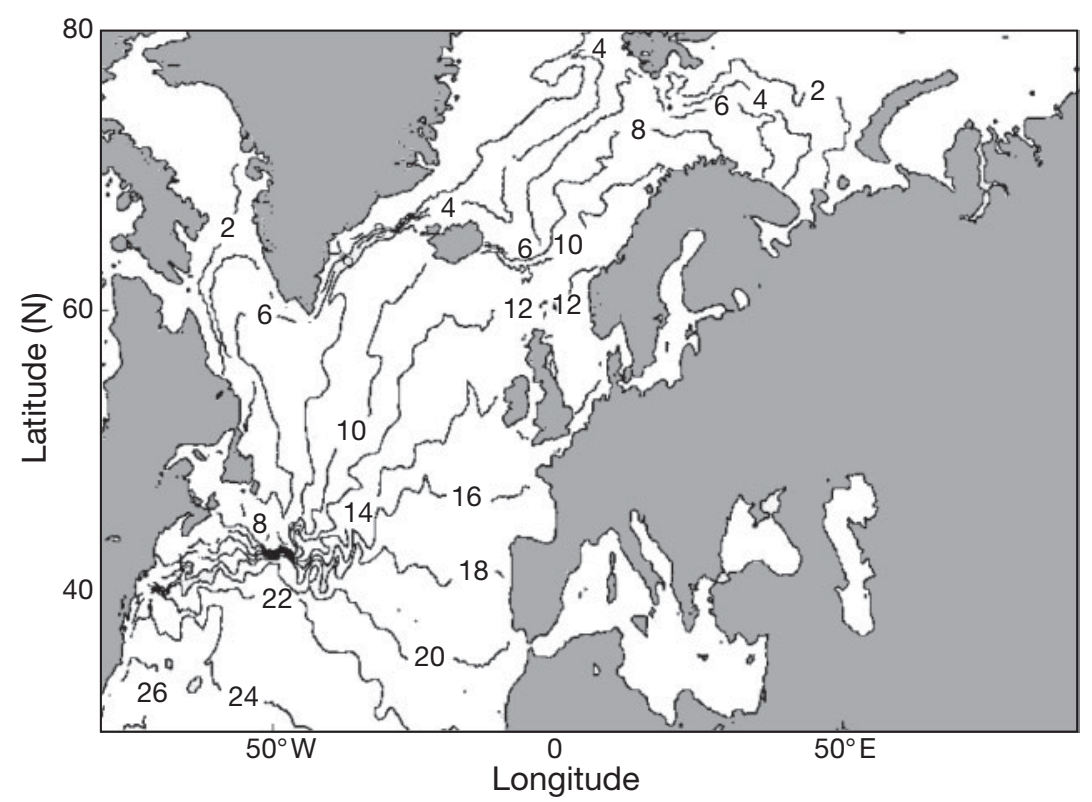

Fig. 10. Contour plot of the Ocean Circulation and Climate Advanced Model (OCCAM) temperature field $\left({ }^{\circ} \mathrm{C}\right)$ in August at a depth of $20 \mathrm{~m}$ the range extends further south when transport is operating, presumably mostly through diffusive spread since the currents are mainly to the north east in this region. Transport also carries the population up to the edge of the summer extent of the sea ice over much of the domain, and allows the population to extend further into the Barents Sea. Interestingly, the population in the Gulf of St. Lawrence is not predicted to persist without transport. This occurs because spring sea ice suppresses the food field in the region during the period of diapause emergence. Transport is also clearly essential in maintaining the population over much of the North Sea where the bathymetry is too shallow to support an overwintering diapause population. Without transport only a few coastal areas where the food levels are very high all year allow a persistent surface population. Overall, abundances are somewhat more uniform without transport, and the centres of abundance in the Labrador-Irminger Sea gyre and the Norwegian Sea gyre are accentuated by transport.

The relatively limited impact of transport on Calanus finmarchicus distribution other than on continental shelves and the distributional limits, might be thought to imply that the population centres on either side of the Atlantic actually represent truly distinct populations. In order to address this issue, we conduct 2 further model runs involving inoculating a single model cell with a population of diapausers at the start of the year and then following the population as it grows and spreads over the domain. In the first run, the inoculated cell is located in the hydrodynamically retentive part of the Labrador Sea, while in the second it is in the Norwegian Sea gyre. The distributions of the C5 to C6s resulting from these runs are shown in Fig. 12 at yearly intervals over the first 6 yr. The population initiated in the Labrador Sea is dispersed throughout the LabradorIrminger Sea gyre by the second year. By the third year, the North Atlantic Drift is carrying individuals into the Norwegian Sea where they once again spread rapidly, and by Year 6 we essentially retrieve the quasi-steady state over the whole domain. By contrast, the Norwegian Sea is somewhat more isolated, but by Year 3 a small stream of individuals from the population initiated there are caught up in the Greenland Coastal Current. These are then swept round the Labrador Sea gyre. In Year 4, some of the newly established Labrador Sea population is being driven back towards the Norwegian Sea by the North Atlantic Drift. By Year 6, the distribution is virtually identical to the one initiated in the Labrador Sea. 


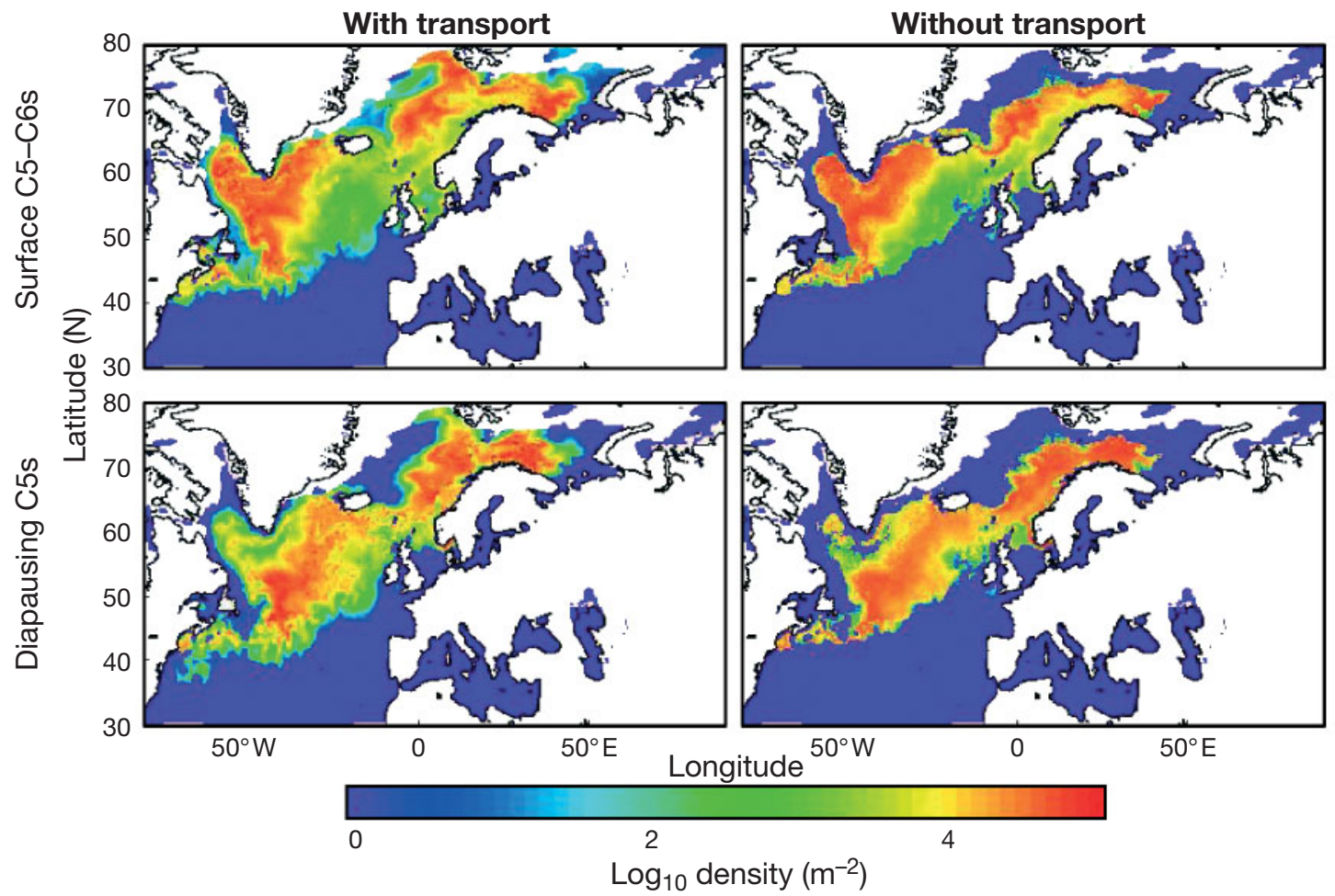

Fig. 11. Effect on the model output of switching off transport. Left-hand panels show surface C5 to C6s (upper panel) and diapausing C5s (lower panel) in July (Day of the year 196) for the model with transport. Right-hand panels show the corresponding output when there is no movement between cells

\section{DISCUSSION}

The model reported in this paper is, to the best of our knowledge, the first characterization of the seasonal demography of Calanus finmarchicus over its entire geographic range. Indeed, we are unaware of any organism with a complex stage-structured life history whose spatial dynamics have been modelled on such a large scale. The size of the domain, coupled with the need for representing both population structure and physical transport by ocean currents, makes any such model computationally demanding. Nonetheless, by adopting the methods developed by Gurney et al. (2001) and Speirs et al. (2005) we were able to obtain run times (on a $3 \mathrm{GHz}$ Pentium IV processor) of about 3 min per model year.

A significant advantage of our methodology is that the model can be run to a steady state yearly cycle very quickly. As can be seen from Fig. 12, the model converges within about 6 simulated years (i.e. about 20 min run time), even when the initial condition is not at all close to the final one. With the exception of Speirs et al. (2005) and some non-spatial models (Hind et al. 2000), all the modelling studies reviewed in the introduction examine short-term dynamics ( $\leq 1 \mathrm{yr}$ ) from an assumed initial condition. Clearly, it is easier to achieve some degree of fit to field data from short term runs, since some correspondence is guaranteed near the initial condition. By contrast, tests involving steady states are more demanding because cumulative errors in closing the yearly cycle can lead to predictions that are not supported by the data. Of course, environmental conditions will change from year to year, and hence the real dynamics of the Calanus finmarchicus population cannot be in a steady state. However, with a convergence time of only a few years, yearly environmental variations would have to be very severe not to make the steady state dynamics a reasonable first approximation.

Computational efficiency also limits the time needed to tune free parameters when fitting to the test data sets. Importantly, this also greatly facilitates the process of model development through falsification. When a model fails to achieve an acceptable fit irrespective of the parameters values, this indicates that structural changes are necessary. This process is illustrated by our initial attempts to expand the Speirs et al. (2005) model to the whole North Atlantic. Although the prototype model had previously been shown to yield a good fit to total copepodite densities in the NE Atlantic, it can now be falsified, mainly by its inability to predict the seasonal cycle of late copepodites (C5 to C6) over the whole North Atlantic, and especially in the Labrador Sea. Although formally the source of the fail- 

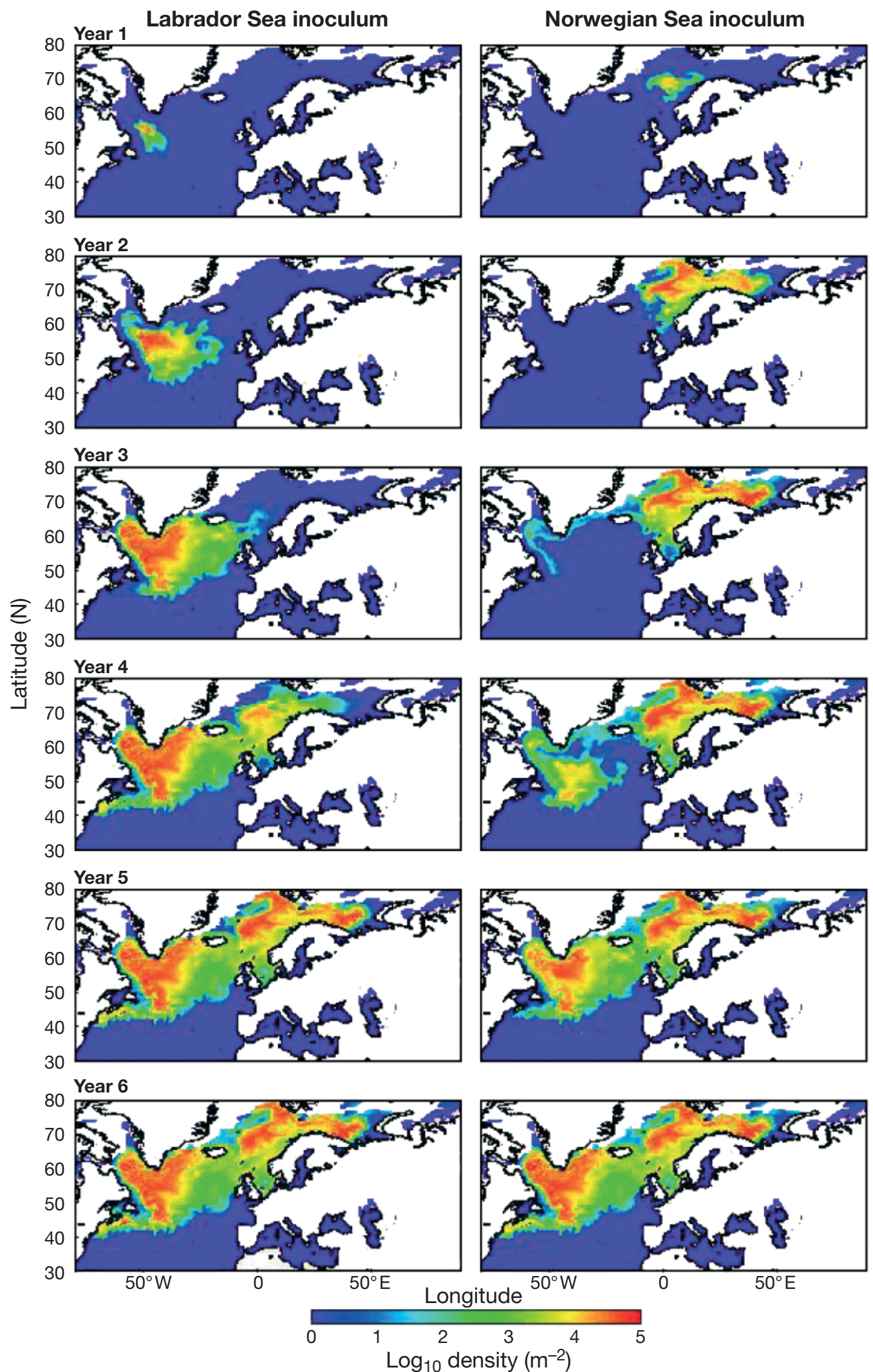

Fig. 12. Spatial distribution of surface C5 to C6s in July (Day of the year 196) in successive years after the release of individuals at a single model cell. Left-hand panels show the spread of an inoculum in the Labrador Sea, while right-hand panels show the corresponding development of a Norwegian Sea inoculum 
ure can be any aspect of the model (including the environmental drivers), it seems more likely to arise through misrepresentations of poorly understood aspects of Calanus finmarchicus biology, in particular diapause and mortality. Our current model therefore contains modifications from the prototype model in the representation of these processes.

The uncertainty in current understanding of diapause initiation is reflected in the variety of approaches used in previous modelling studies. For example, Carlotti \& Wolf (1998) allowed diapause to occur variably during C4 and C5 depending on lipid reserves. Miller et al. (1998) assumed that a fraction of all individuals reaching the end of the C5 stage enter diapause, and that this fraction is greater for the first surface generation than for the second. Hind et al. (2000) concluded that diapause entry was cued when individuals entering the C5 stage experienced low food levels. Heath et al. (2000a) used the same approach. In order to match a bimodality in their data, Pedersen et al. (2000) assumed that $20 \%$ of the population diapaused in late $\mathrm{C} 4$ while $80 \%$ of the population diapaused in late C5. The behavioural model of Fiksen (2000) cues diapause entry in a similar way to Carlotti \& Wolf (1998), but only during the C5 stage. Tittensor et al. (2003) allow individuals to enter diapause at a constant rate throughout the C5 stage, while Zakardjian et al. (2003) had a similar approach but with a seasonally varying rate. It has also been suggested that the arrival of seasonally migrating fish can promote diapause entry (Kaartvedt 2000), although the difficulties of representing predator fields means this has never been included in a demographic model.

The Speirs et al. (2005) model uses the same diapause entry model as Hind et al. (2000), and initially this formed the basis for our current model. However, the falsification of that scheme in the tests presented here, together with the observations that first generation $\mathrm{C} 5 \mathrm{~s}$ are seen in both the surface and then as overwinterers at a time of high food abundance suggests that this cannot be correct. Instead we are forced to adopt the simpler notion that a fixed fraction of each generation enters diapause at the end of the C5 stage, in a manner similar to that proposed by Miller et al. (1998). Since the population remains in C5 over the winter, the model carries the biological implication that diapause is essentially a state of arrested development. The process of 'development' through the diapause classes then represents only the use of lipid reserves during overwintering (Ingvarsdottir et al. 1999). This interpretation contrasts with that of Hind et al. (2000), whereby diapause is initiated at the start of $\mathrm{C} 5$ and results from a reduced development rate through that stage.

Although we have settled on the end of C5 as the stage where diapause occurs, we interpret this as rep- resenting only the dominant stage. It is known that $\mathrm{C} 4 \mathrm{~s}$ can be present in the overwintering population in quite high numbers (Irigoien 1999, Heath et al. 2004). It seems therefore likely that diapause can be initiated at any stage from late C4 through to the end of C5. Irigoien (2004) has convincingly argued that entry into diapause occurs when an individual has accumulated sufficient lipids to survive overwintering, and that this might occur at a variety of developmental stages. If there is some degree of stochasticity in the accumulation of lipids by individual Calanus, this could lead to something akin to a fixed fraction of individuals entering diapause in each generation. Although our model does not represent resource accumulation, we carried out some runs (not reported here) in which the diapausing fraction depends on food abundance; however, we were unable to obtain any improvement on the fixed fraction model. In practice, it may not be possible to distinguish between the demography arising from fixed-fraction or resource-based models on the basis of currently available data.

The other major uncertainty in modelling Calanus finmarchicus populations is mortality (Ohman et al. 2004). Since most modelling studies have only dealt with short-term dynamics, they generally use constant stage-dependent rates that are picked to yield plausible relative abundances between the developmental stages, or else use field estimates of total mortality. In order to introduce the density-dependence required to regulate the population in multi-year runs, we adopt the scheme of Speirs et al. (2005) which makes mortality proportional to the $C$. finmarchicus biomass while retaining the relative differences in mortality between the developmental stages. In its original form this caused problems in the predicted dynamics in the Labrador Sea. In that region, the main population peak of C5 to C6s occurs during July to August, significantly later than in most other regions of the North Atlantic (Planque et al. 1997, Tittensor et al. 2003). The cold water of the region slows development so that the bulk of the first summer generation matures at that time, but mortality acting over this lengthened development depletes the population numbers. Although the distinctive Labrador Sea dynamics might conceivably arise through phenotypic differences in the local population, we reject this possibility given the high degree of physical connectivity between the various parts of the distribution of $C$. finmarchicus. Instead, we argue that the observed high late summer abundances of C5 to $\mathrm{C} 6$ can only arise if the mortality rate there is low. Since the region is cold, this implies a temperaturedependent mortality rate.

Although our temperature-dependent mortality rate is ad hoc, the role of temperature in the ecology and distribution of marine species is widely recognized 
(e.g. Sanford 1999, Hays et al. 2005). Moreover, some previous studies have noted an apparent association between mortality and temperature among the Copepoda. Myers \& Runge (1983, 1986), Runge \& Myers (1986) and showed that the inverse relationship between temperature and adult body size among the marine Copepoda is the opposite of that predicted by life-history theory unless mortality increases with temperature. More recently, Hirst \& Kiørboe (2002) used the balanced mortality hypothesis to estimate average mortality rates for a wide range of marine copepod species and found a significant positive association between temperature and mortality. Despite these results, the underlying mechanisms remain unknown. A direct effect of temperature on mortality rates seems unlikely, although it is conceivable that a physiological inability to meet increasing metabolic costs as temperature increases may yield something of the kind. It seems more probable that our mortality model is a proxy for a complex range of processes, possibly including the differential impact of predators in surface waters of different temperature.

In the light of the apparent association between the 2 Calanus finmarchicus population centres and the 2 gyres in the Labrador-Irminger Sea and the Norwegian Sea, one of the more surprising results of our study is the apparently limited impact of eliminating transport. Despite this, the well-established effects of transport in moving oceanic stock on to the shelf regions, such as the North Sea (Heath et al. 1999a, Harms et al. 2000), and into the Barents Sea (Slagstad \& Tande 1996) were still apparent. The results also showed that some of the production in the south, and even more in the north, of the distribution was due to transported individuals. Transport did accentuate the importance of the more retentive gyre areas, although the effect was not substantial. We conclude from this that, while on shelf regions and at the limits of the geographic range transport is of great importance, its direct effect (i.e. not including any associated impact on temperature and food) on the basin-scale dynamics is more modest.

This result was all the more striking when in our final experiments the release of inocula showed that there was a high degree of connectivity over the whole domain. These suggest a time scale of about 6 yr for the transport of the Calanus finmarchicus population between the 2 main gyre systems, and the consequent approach to the population steady state. This time scale agrees remarkably well with the transport of the 'great salinity anomaly' observed in the North Atlantic during the 1970s (Dickson et al. 1988, Aksnes \& Blindheim 1996). This body of low salinity water originated in the late 1960s in polar water north of Iceland. By 1972, it was observed in the Labrador Sea, and 6 yr later had travelled with the North Atlantic drift into the
North Sea and all along the Norwegian coast. Time scales as short as this imply quite substantial gene flow over the geographic range of $C$. finmarchicus. This appears to be in line with the studies of Bucklin \& Kocher (1996) and Bucklin et al. (1996), which suggest on the basis of restriction fragment length polymorphisms of mitochondrial DNA that there is little genetic differentiation among $C$. finmarchicus subpopulations.

Taken together, the simulations on transport and domain connectivity indicate substantial population movement over the domain but with limited demographic impact other than on the distribution boundaries and shelf seas. This demonstrates, firstly, that advective losses from the 2 main gyre systems of the Labrador-Irminger Sea and the Norwegian Sea do not significantly reduce the population there, and hence provides confirmation of the conclusions of Aksnes \& Blindheim (1996) that biological production of Calanus finmarchicus does indeed dominate over advective losses at large spatial scales. At smaller spatial and time scales than those represented by our present model, spatial and temporal environmental heterogeneity can play an important role in determining the details of the observed demography (Speirs et al. 2004). However, the modest effect of transport on the spatial patterns of abundance in our simulations demonstrates that the stage structure of individuals being transported into any given location must be similar to those being transported out. This can only occur if the flow fields are not divergent and the spatial scale over which significant variation in the environmental drivers occurs is larger than the distances travelled by individual Calanus during their lifetimes.

Acknowledgements. This work was supported by the NERC Marine Productivity Directed Programme (UK GLOBEC) under grant NER/T/S/2002/00142. SeaWiFS data composites were supplied by the remote sensing team at Plymouth Marine Laboratory (also funded by NERC MarProd). Darren Stevens of the Sir Alister Hardy Foundation for Ocean Science kindly extracted the Calanus data from the CPR database. The EU-funded TASC project supported much of the field sampling data, and we thank Astthor Gislason for the Westmann Islands data and the Norwegian team for supplying the OWS Mike data. The OWS India data were digitized as part of the NERC PRIME programme. We are grateful to Ted Durbin and the members of the US GLOBEC programme for the use of their Gulf of Maine data. Finally, we thank 3 anonymous referees for their constructive comments.

\section{LITERATURE CITED}

Aksnes DL, Blindheim J (1996) Circulation patterns in the North Atlantic and possible impact on population dynamics of Calanus finmarchicus. Ophelia 44:7-28

Beare DJ, McKenzie E, Speirs DC (1998) Unstable seasonality of Calanus finmarchicus in the Fair Isle current. J Mar Biol Assoc UK 78:1377-1380 
Bryant AD, Heath M, Gurney WSC, Beare DJ, Robertson W (1997) The seasonal dynamics of Calanus finmarchicus: development of a three-dimensional structured population model and application to the northern North Sea. J Sea Res 38:361-379

Bryant AD, Hainbucher D, Heath M (1998) Basin-scale advection and population persistence of Calanus finmarchicus. Fish Oceanogr 7:235-244

Bucklin A, Kocher TD (1996) Source regions for recruitment of Calanus finmarchicus to Georges Bank: evidence from molecular population genetic analysis of mtDNA. DeepSea Res II 43:1665-1681

Bucklin A, Sundt R, Dahle G (1996) The population genetics of Calanus finmarchicus in the North Atlantic. Ophelia $44: 29-45$

Campbell RG, Wagner MW, Teegarden GJ, Boudreau CA, Durbin EG (2001) Growth and development of the copepod Calanus finmarchicus reared in the laboratory. Mar Ecol Prog Ser 221:161-183

Carlotti F (1996) A realistic physical-biological model for Calanus finmarchicus in the North Atlantic. Ophelia $44: 47-58$

Carlotti F, Radach G (1996) Seasonal dynamics of phytoplankton and Calanus finmarchicus in the North Sea as revealed by a coupled one-dimensional model. Limnol Oceanogr 41:522-539

Carlotti F, Wolf KU (1998) A Lagrangian ensemble model of Calanus finmarchicus coupled with a 1-D ecosystem model. Fish Oceanogr 7:191-204

Clarke ED, Speirs DC, Heath MR, Wood SN, Gurney WSC, Holmes SJ (2006) Using remote sensed data to model chlorophyll a: an application of anisotropic thin plate regression splines. J R Stat Soc C (in press)

Colebrook J (1986) Environmental influences on long-term variability in marine plankton. Hydrobiologia 44:29-45

Comiso J (1999) Bootstrap sea ice concentrations from Nimbus-7 SMMR and DMSP SSM/I. National Snow and Ices Data Center, Boulder, CO, USA. Digital media (updated 2002)

Conover RJ (1988) Comparative life histories in the genera Calanus and Neocalanus in high latitudes of the northern hemisphere. Hydrobiologia 167:127-142

Dalpadado P, Ellersten B, Melle W, Dommasnes A (2000) Food and feeding conditions of Norwegian springspawning herring (Clupea harengus). ICES J Mar Sci 57: $843-857$

de Young B, Heath M, Werner F, Chai F, Magrey B, Monfray P (2004) Challenges of modeling ocean basin ecosystems. Science 304:1463-1466

Dickson RR, Meincke J, Malmberg SA, Lee A (1988) The 'great salinity anomaly' in the northern Atlantic. Prog Oceanogr 20:103-151

Durbin EG, Garrahan PR, Casas MC (2000) Abundance and distribution of Calanus finmarchicus on the Georges bank during 1995 and 1996. ICES J Mar Sci 57:1664-1685

Eiane K, Aksnes DL, Ohman MD, Wood SN, Martinussen MB (2002) Stage-specific mortality of Calanus spp. under different predation regimes. Limnol Oceanogr 47:636-645

Fiksen $\varnothing$ (2000) The adaptive timing of diapause-a search for evolutionary robust strategies in Calanus finmarchicus. ICES J Mar Sci 57:1825-1833

Gislason A, Ástthórsson OS, Petursdóttir H, Gudfinnsson H, Bodvarsdóttir AR (2000) Life cycle of Calanus finmarchicus south of Iceland in relation to hydrography and chlorophyll a. ICES J Mar Sci 57:1619-1627

Greene CH, Pershing AJ, Conversi A, Planque B and 10 others (2003) Trans-Atlantic responses of Calanus finmarchi- cus populations to basin-scale forcing associated with the North Atlantic Oscillation. Prog Oceanogr 58:301-312

Gurney WSC, Speirs DC, Wood SN, Clarke ED, Heath MR (2001) Simulating spatially and physiologically structured populations. J Anim Ecol 70:881-894

Hannah CG, Naimie CE, Loder JW, Werner FE (1998) Upperocean transport mechanisms from the Gulf of Maine to Georges Bank, with implications for Calanus supply. Cont Shelf Res 17:1887-1911

Harms IH, Heath MR, Bryant AD, Backhaus JO, Hainbucher DA (2000) Modelling the Northeast Atalntic circulation: implications for the spring invasion of shelf regions by Calanus finmarchicus. ICES J Mar Sci 57:1-14

Hays GC, Richardson AJ, Robinson C (2005) Climate change and marine plankton. Trends Ecol Evol 20:337-344

Head EJH, Harris LR, Campbell RW (2000) Investigations on the ecology of Calanus spp. in the Labrador Sea I. Relationship between the phytoplankton bloom and reproduction and development of Calanus finmarchicus in spring. Mar Ecol Prog Ser 193:53-73

Head EJH, Harris LR, Yashayaev I (2003) Distributions of Calanus spp. and other meso zooplankton in the Labrador sea in relation to hydrography in spring and summer (1995-2000). Prog Oceanogr 59:1-30

Heath M, Roberston W, Mardaljevic J, Gurney WSC (1997) Modelling the population dynamics of Calanus in the Fair Isle Current off northern Scotland. J Sea Res 38:381-412

Heath M, Backhaus J, Richardson K, McKenzie E and 7 others (1999a) Climate fluctuations and the spring invasion of the North Sea by Calanus finmarchicus. Fish Oceanogr 8: 163-176

Heath M, Dunn J, Fraser J, Hay S, Madden H (1999b) Field calibration of the optical plankton counter with respect to Calanus finmarchicus. Fish Oceanogr 8:13-24

Heath MR, Ástthórsson OS, Dunn J, Ellertsen B and 10 others (2000a) Comparative analysis of Calanus finmarchicus demography at locations around the Northeast Atlantic. ICES J Mar Sci 57:1562-1580

Heath MR, Fraser JG, Gislason A, Hay SJ, Jónasdóttir SH, Richardson K (2000b) Winter distribution of Calanus finmarchicus in the Northeast Atlantic. ICES J Mar Sci $57: 1628-1635$

Heath M, Carlotti F, de Young B, Fiksen Ø, Werner C (2001) Secondary production in the oceans and the response to climate change. ICES/GLOBEC Newsl 8:4-6

Heath MR, Boyle PR, Gislason A, Gurney WSC and 12 others (2004) Comparative ecology of overwintering Calanus finmarchicus in the North Atlantic and implications for life cycle patterns. ICES J Mar Sci 61:698-708

Hind A, Gurney W (1998) Life-cycle synchrony in a marine copepod. Arch Hydrobiol 52:327-337

Hind AD, Gurney WSC, Heath M, Bryant AD (2000) Overwintering strategies in Calanus finmarchicus. Mar Ecol Prog Ser 193:95-107

Hirche HJ (1997) Diapause in Calanus finmarchicus-a review. Ophelia 44:129-143

Hirche HJ, Meyer U, Niehoff B (1997) Egg production of Calanus finmarchicus: effect of temperature, food and season. Mar Biol 127:609-620

Hirche HJ, Brey T, Niehoff B (2001) A high-frequency time series at Ocean Weather Ship Station M (Norwegian Sea): population dynamics of Calanus finmarchicus. Mar Ecol Prog Ser 219:205-219

Hirst AG, Kiørboe T (2002) Mortality of marine planktonic copepods: global rates and patterns. Mar Ecol Prog Ser 230:195-209

Ingvarsdottir A, Houlihan DF, Heath MR, Hay SJ (1999) Sea- 
sonal changes in respiration rates of copepodite stage $\mathrm{V}$ Calanus finmarchicus (Gunnerus). Fish Oceanogr 8:73-83 Irigoien X (1999) Vertical distribution and population structure of Calanus finmarchicus at station India $\left(59^{\circ} \mathrm{N}, 19^{\circ} \mathrm{W}\right)$ during the passage of the great salinity anomaly, 1971-1975. Deep-Sea Res I 47:1-26

Irigoien X (2004) Some ideas about the role of lipids in the life cycle of Calanus finmarchicus. J Plankton Res 26:259-263

Jaschnov WA (1970) Distribution of Calanus species in the seas of the northern hemisphere. Int Rev Gesamten Hydrobiol 55:197-212

Kaartvedt S (2000) Life history of Calanus finmarchicus in the Norwegian Sea in relation to planktivorous fish. ICES J Mar Sci 57:1819-1824

Lynch DR, Gentleman WC, McGillicuddy DJ Jr, Davis CS (1998) Biological/physical simulations of Calanus finmarchicus population dynamics in the Gulf of Maine. Mar Ecol Prog Ser 169:189-210

Lynch DR, Lewis CVW, Werner FE (2001) Can Georges Bank larval cod survive on a calanoid diet? Deep-Sea Res II 48:609-630

MERCINA (2004) Working group on marine ecosystems response to climate change in the North Atlantic. Supplyside ecology and the response of zooplankton to climatedriven changes in North Atlantic ocean circulation. Oceanogr 17:60-71

Miller C, Tande K (1993) Stage duration estimation for Calanus populations, a modelling study. Mar Ecol Prog Ser 102:15-34

Miller CB, Lynch DR, Carlotti F, Gentleman W, Lewis CVW (1998) Coupling of an individual-based population dynamic model of Calanus finmarchicus to a circulation model for the Georges Bank region. Fish Oceanogr $7: 219-234$

Myers RA, Runge JA (1983) Predictions of seasonal natural mortality rates in a copepod population using life-history theory. Mar Ecol Prog Ser 11:189-194

Myers RA, Runge JA (1986) Temperature-dependent changes in copepod adult size: an evolutionary theory. In: Schriever G, Schminke H, Shih C-t (eds) Proc Second Int Conf Copepoda. National Museums of Canada, Syllogeus No. 58: 374-378

Nichols J, Thompson A (1991) Mesh selection of copepodite and naupliar stages of four calanoid copepod species. J Plankton Res 13:661-671

Ohman MD, Eiane K, Durbin EG, Runge JA, Hirche HJ (2004) A comparative study of Calanus finmarchicus mortality patterns at five localities in the North Atlantic. ICES J Mar Sci 61:687-697

Parsons T, Takahashi M, Hargrave B (1984) Biological

Editorial responsibility: Thomas Kiørboe (Contributing Editor), Charlottenlund, Denmark oceanographic processes, 3rd edn. Pergamon Press, Oxford

Pedersen OP, Tande KS, Timonin A, Semenova T (2000) A possible connection between hydrography and the distribution of Calanus finmarchicus on the Norwegian midshelf in 1997. ICES J Mar Sci 57:1645-1655

Pedersen OP, Tande KS, Slagstad D (2001) A model study of demography and spatial distribution of Calanus finmarchicus at the Norwegian coast. Deep-Sea Res II 48:567-587

Planque B, Hays GC, Ibañez F, Gamble JC (1997) Large scale spatial variations in the seasonal abundance of Calanus finmarchicus. Deep-Sea Res II 44:315-326

Runge JA, Myers RA (1986) Constraints on the evolution of copepod body size. In: Schriever G, Schminke H, Shih C-t (eds) Proc Second Int Conf Copepoda. National Museums of Canada, Syllogeus No. 58:443-447

Sanford E (1999) Regulation of keystone predation by small changes in ocean temperature. Science 283:2095-2097

Slagstad D, Tande KS (1996) The importance of seasonal vertical migration in across shelf transport of Calanus finmarchicus. Ophelia 44:189-205

Snyder J (1982) Map projections used by the US Geological Survey. Bull US Geol Surv 1532

Speirs DC, Gurney WSC (2001) Population persistence in rivers and estuaries. Ecology 82:1219-1237

Speirs DC, Gurney WSC, Holmes SJ, Heath MR and 5 others (2004) Understanding demography in an advective environment: Modelling Calanus finmarchicus in the Norwegian Sea. J Anim Ecol 73:897-910

Speirs DC, Gurney WSC, Heath MR, Wood SN (2005) Modelling the basin-scale demography of Calanus finmarchicus in the north-east Atlantic. Fish Oceanogr 14:333-358

Tittensor DP, de Young B, Tang CL (2003) Modelling the distribution, sustainability and diapause emergence timing of the copepod Calanus finmarchicus in the Labrador Sea. Fish Oceanogr 12:299-316

Warner AJ, Hays GC (1994) Sampling by the continous plankton recorder survey. Prog Oceanogr 34:237-256

Webb DJ, de Cuevas BA, Coward AC (1998) The first main run of the OCCAM global ocean model. Internal Document 34, Southampton Oceanography Centre, Southhampton

Zakardjian BA, Sheng J, Runge JA, McLaren I, Plourde S, Thompson KR, Gratton Y (2003) Effects of temperature and circulation on the population dynamics of Calanus finmarchicus in the Gulf of St. Lawrence and Scotian Shelf: Study with a coupled, three-dimensional hydrodynamic, stage-based life-history model. J Geophys Res 108 (C11), 8016, doi:10.1029/2002JC001410

Submitted: January 18, 2005; Accepted: September 16, 2005 Proofs received from author(s): April 3, 2006 